
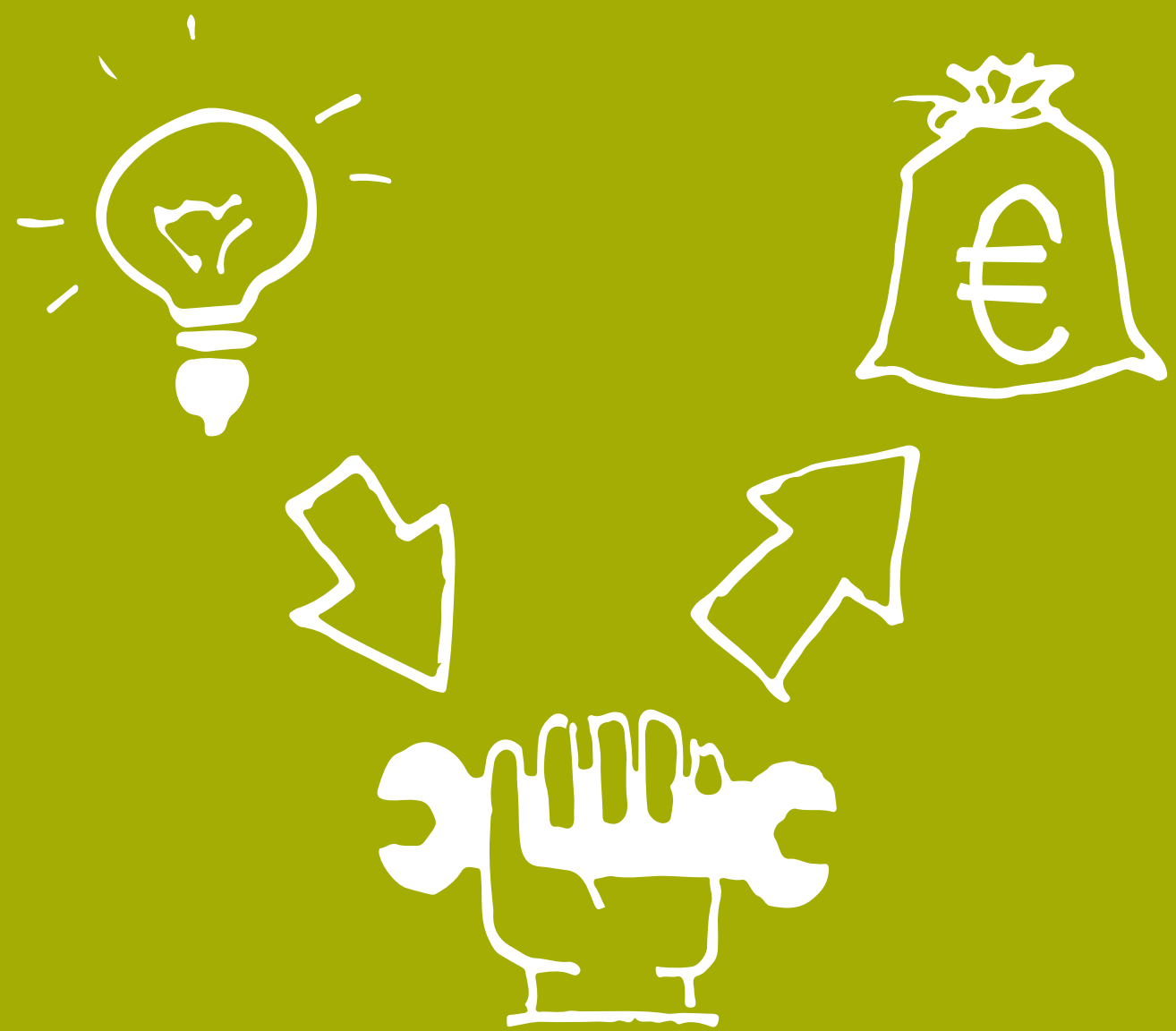


\section{3c empresa. Investigación y pensamiento crítico.}

Periodicidad trimestral. Quarterly periodicity.

Edición 34. Volumen 7, Número 2 (Mayo - agosto '18). Edition 34, Volume 7, Issue 2 (May - August '18).

Tirada nacional e internacional. National and internacional circulation.

Artículos revisados por el método de evaluación de pares de doble ciego. Articles reviewed by the double blind peer evaluation method.

ISSN: 2254-3376

$\mathrm{N}^{\circ}$ de Depósito Legal: A $268-2012$

DOI: http://dx.doi.org/10.17993/3cemp.2018.070234

Edita:

Área de Innovación y Desarrollo, S.L.

C/ Els Alzamora 17, Alcoy, Alicante (España)

Tel: 965030572

info@3ciencias.com _www.3ciencias.com

Todos los derechos reservados. Se autoriza la reproducción total o parcial de los artículos citando 1 a fuente y el autor. This publication may be reproduced by mentioning the source and the authors. Copyright (C) Área de Innovación y Desarrollo, S.L.

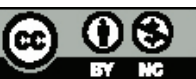


(3) empresa 


\section{Objetivo editorial}

La Editorial científica 3Ciencias pretende transmitir a la sociedad ideas y proyectos innovadores, plasmados, o bien en artículos originales sometidos a revisión por expertos, o bien en los libros publicados con la más alta calidad científica y técnica.

\section{Nuestro público}

- Personal investigador.

- Doctorandos.

- Profesores de universidad.

- Oficinas de transferencia de resultados de investigación (OTRI).

- Empresas que desarrollan labor investigadora y quieran publicar alguno de sus estudios.

\section{Cobertura temática}

La Revista 3C Empresa es una revista de carácter científico-social donde se difunden trabajos originales de investigación que abarcan diferentes temáticas relacionadas con las ciencias sociales, entre las que destacan la economía, la gestión empresarial e institucional y el ámbito educacional.

\section{Información para autores}

Toda la información sobre el envío de originales se puede encontrar en el siguiente enlace: http://www.3ciencias.com/normas-de-publicacion/instrucciones-para-el-envio-de-articulos/ 


\section{Publishing goal}

3Ciencias wants to transmit to society innovative projects and ideas. This goal is reached thought the publication of original articles which are subdue to peer review or thorough the publication of scientific books.

\section{Our target}

- Research staff.

- PhD students.

- Professors.

- Research Results Transfer Office.

- Companies that develop research and want to publish some of their works.

\section{Tematic coverage}

3c Empresa journal is a scientific-social journal, where original works are disseminated. These works cover different themes related to social sciences, such as economy, business and educational management.

\section{Instructions for authors}

All information about sending originals can be found at the following link: https://www.3ciencias.com/en/regulations/instructions/ 


\section{Indizado por}

Indexed by

Plataforma de evaluación de revistas
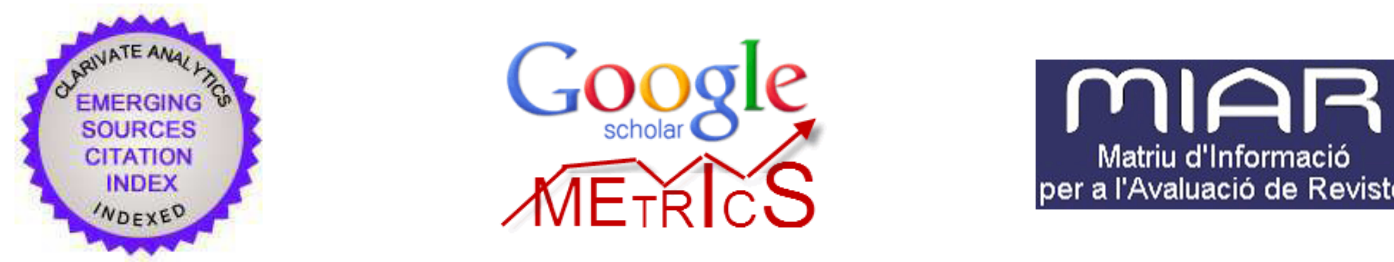

Matriu d'Informació

per a l'Avaluació de Revistes

Bases de datos internacionales selectivas

\section{EBSCOhost}

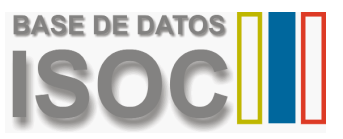

Business Source

\# Premier

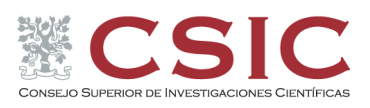

$\cap \leadsto \mid \begin{aligned} & \text { DIRECTORY OF } \\ & \text { OPEN ACCESS } \\ & \text { JOURNALS }\end{aligned}$

Susiness

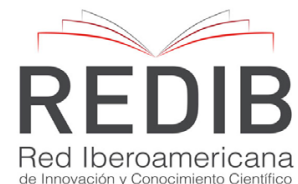

Red lberoamericana

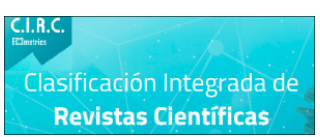

OAJ $\begin{aligned} & \text { Open Academic } \\ & \text { Journals Index }\end{aligned}$ 
Directorios selectivos

\section{latindex}

Hemerotecas selectivas

\section{O Dialnet}

Buscadores de literatura científica en acceso abierto 


\section{/SUMARIO/}


¿Es la exportación un elemento relevante para explicar el rendimiento de una empresa? El caso de las pymes gallegas para el período 2002 - 2013

Is export a relevant element to explain the performance of a company? The case of Galician SMEs for the period 2002-2013

José Pablo Abeal Vázque, Begoña Álvarez García y Javier Tarrío Saavedra

Mujeres rurales emprendedoras, detonadoras de desarrollo económico: binomio colaboración - empoderamiento

Entrepreneurial rural women, economic development detoners: binding collaboration - empowerment

Isabel Pérez Pérez

Análisis de calidad de vida laboral y competitividad en empresas de servicios turísticos

Quality of work life and competitiveness in tourist service company

José Octavio Molina Germán, Anel Yadira Pérez Melo, Georgina Lizárraga Salazar y Ana María

Larrañaga Núñez

Bahía de Altata, Navolato - Nuevo modelo de desarrollo turístico sostenible Altata Bay, Navolato - New sustainable touristic model of development

Martín León Santiesteban y Juan Pablo Mariño Jiménez

Plan estratégico para la reactivación económica de San Antonio, municipio de La Paz, Baja California Sur, México

Strategic plan for the economic reactivation of San Antonio, La Paz municipality, Baja California Sur, Mexico

Miguel Ángel Ojeda-Ruiz, Sergio Antonio Bianchi-Estraday yJosé Emer García de la Puente-

Orozco 
/01/ 


\section{¿Es la exportación un elemento relevante para explicar el rendimiento de una empresa? El caso de las pymes gallegas para el período 2002 - 2013}

Is export a relevant element to explain the performance of a company? The case of Galician SMEs for the period 2002-2013

José Pablo Abeal Vázquez

Profesor Contratado Interino. Doctor en Economía por la UDC. Departamento de Empresa. Universidade da Coruña. A Coruña. España.

jpabeal@udc.es

Begoña Álvarez García

Profesora Contratada Doctor. Doctora en Economía por la UDC. Departamento de Empresa. Universidade da Coruña. A Coruña. España.

balvarez@udc.es

Javier Tarrío Saavedra

Profesor Contratado Interino. Doctor en Estadística por la UDC. Departamento de Matemáticas. Universidade da Coruña. A Coruña. España.

javier.tarrio@udc.es

Recepción: 24/03/2017. Aceptación: 02/04/2017. Publicación: 24/05/2018

Citación sugerida:

Abeal Vázquez, J.P., Álvarez García, B. y Tarrío Saavedra, J. (2018). ¿Es la exportación un elemento relevante para explicar el rendimiento de una empresa? El caso de las pymes gallegas para el período 2002-2013. 3C Empresa: investigación y pensamiento crítico, 7(2), 10-25. DOI: http://dx.doi. org/10.17993/3cemp.2018.070234.10-25/ 


\section{RESUMEN}

El principal objetivo de este trabajo es averiguar en qué medida el hecho de que una empresa sea exportadora tiene consecuencias sobre su rendimiento. El caso de estudio, elaborado a partir de la base de datos ARDAN, se encuadra dentro de la región española de Galicia. El período temporal comprende desde el año 2002 hasta 2013. La muestra recoge únicamente PYMEs. El análisis empírico parte de un conjunto de variables empresariales ligadas a la gestión, a factores fijos como la localización, y a la coyuntura económica. Los resultados obtenidos con las técnicas de análisis aplicadas no son concluyentes y queda el camino abierto a nuevas investigaciones.

\section{ABSTRACT}

The main objective of this work is to find out to what extent the fact that a company is an exporter has consequences on its performance. The case study, developed from ARDAN database, is focused on the Spanish region of Galicia. The temporary period covers from 2002 to 2013. The sample includes only SMEs. The empirical analysis starts from a set of business variables linked to management, fixed factors such as location and to the economic situation. The results obtained with the analytical techniques applied are not conclusive and the way is open to new investigations.

\section{PALABRAS CLAVE}

Rendimiento empresarial, Características de las empresas, PYMES, Exportación, Análisis multivariante.

\section{KEY WORDS}

Firm performance, Firm characteristics, SME's, Exporting, Multivariate analysis. 


\section{INTRODUCCIÓN}

El binomio entre la actuación de la empresa y su enfoque internacional es una cuestión ampliamente abordada dentro de la investigación económica y desde perspectivas muy variadas durante las últimas décadas (Li, 2007). Sin embargo, se trata de un tema de gran complejidad donde las conclusiones distan de ser unánimes y los interrogantes siguen abiertos y sin perspectivas de una posición común al respecto (Glaum y Oesterle, 2007; Kamakura, Ramón-Jerónimo y Vecino, 2012; Majochi, Dalla y D’Angelo, 2015). En este sentido, las soluciones se asimilan a cada caso de estudio y a unas características concretas.

Las teorías que han servido como soporte a los diferentes autores para sus análisis son muy heterogéneas. Sin embargo, podemos destacar que gran parte de la literatura consideran la internacionalización como un proceso evolutivo (Johanson y Vahlne, 1977), donde las empresas aumentan gradualmente su interés por las operaciones internacionales al considerarlas un factor impulsor de su crecimiento (Kamakura et al., 2012).

Por otra parte, el criterio de proximidad geográfica o cultural suele considerarse una de las claves a la hora de señalar los primeros destinos de exportación. A medida que las empresas afianzan su conocimiento de los mercados internacionales, estas van dando el salto hacia métodos más directos de exportación. No obstante, a partir de la última década del siglo pasado, adquirió fuerza un enfoque que intentaba explicar el hecho, cada vez más relevante, de aquellas empresas que nacían globales o que se transformaban en globales con rapidez (Oviatt y McDougall, 1994).

\section{A medida que las empresas afianzan su conocimiento de los mercados} internacionales, estas van dando el salto hacia métodos más directos de exportación.

El objetivo básico de este trabajo es contrastar, para las pymes gallegas en el período 2002-2013, el papel que juega la exportación para explicar su rendimiento. Para ello, se integra la variable exportación dentro de un modelo que incluye un conjunto de variables internas de cada empresa y de su entorno. El análisis propuesto es exploratorio. A partir de un análisis descriptivo inicial, se plantea un análisis de la varianza y un modelo explicativo mediante una regresión lineal múltiple. A continuación, se plantean brevemente las conclusiones y algunas de las posibles futuras líneas de investigación a desarrollar. 


\section{ESTADO DEL ARTE}

La variedad de teorías, metodologías, datos y conclusiones en la literatura demuestran la falta de consenso en torno a la relación existente entre el rendimiento de las empresas y su capacidad para exportar. Así, algunos autores encontraron evidencia empírica que demostraba la relación positiva entre la actividad exportadora y el rendimiento empresarial en base a una mayor fortaleza competitiva (e. g. Bernard y Jensen, 1999; Ling-Yee, 2004; Annavarjula y Beldona, 2005; Pangarkar, 2008; Ellis, Davies y Wong, 2011).

Otros autores, en cambio, concluyen que, justificado por el principio económico del rendimiento marginal decreciente, la relación puede tener forma de U invertida (Gomes y Ramaswamy, 1999; Li y Qian, 2005). También tenemos aproximaciones que nos hablan de una forma de S, mostrando un proceso de convergencia, deterioro, reorientación y vuelta a la convergencia (Contractor, Kundu y Hsu, 2003; Lu y Beamish, 2004). Incluso, algunos estudios, no encuentran una relación significativa (Ramírez-Aleson y Espitia-Escuer, 2001).

Desde otra perspectiva, Bernard y Jensen (1999) encontraron evidencia empírica de que la actividad de exportar no es causa del incremento de la productividad, pero genera oportunidades de expansión para las empresas con mayor productividad, lo que se traduce en un empleo más estable. A su vez, Yi y Wang (2012) y Serti y Tomasi (2014), demuestran que las variables tamaño y productividad están positivamente relacionadas con la probabilidad de exportar y que la localización y la cercanía a otros exportadores también son dos elementos que contribuyen a reducir costes y lanzarse a exportar.

Desde la perspectiva de las pequeñas y medianas empresas, y para el caso de Italia, Giovannetti, Ricchiuti y Velucchi (2013) demuestran que existe una relación evidente entre el contexto socioeconómico (localización geográfica, cercanía a las infraestructuras, etc.) y su rendimiento y la propensión a exportar. Sin embargo, esta relación es mucho menor en el caso de las grandes empresas.

Otro ejemplo que ilustra la variedad en las conclusiones es el trabajo de Serra, Pointon y Abdou (2012). En él analizan las empresas del sector textil de Reino Unido y Portugal y observan resultados distintos en ambos países: por ejemplo, el tamaño de las empresas es importante en el caso de Portugal, pero no en Reino Unido. 
A la heterogeneidad comentada anteriormente, hay que añadir que abundan los estudios en la literatura que realizan un análisis muy profundo pero a partir de un pequeño número de empresas durante un período de tiempo no muy largo (e. g. Pangarkar, 2008; Majochi et al., 2015; Boehe, Qian y Peng, 2016). Esta aproximación, según indican Kamakura et al. (2012), no siempre capta la naturaleza dinámica de las exportaciones.

Con respecto al tamaño de las empresas analizadas, aunque los trabajos que tienen en cuenta a grandes empresas que cotizan en Bolsa es abundante (Gourlay y Seaton, 2004; Li y Qian, 2005; Annavarjula y Beldona, 2005; Glaum y Oesterle 2007), cada vez son más los autores que enfocan sus estudios hacia las pymes (Westhead, Wright y Ucbasaran, 2001; Kalinic y Forza, 2012; Majochhi et al. 2015).

No todas las variables influyen de igual forma en el proceso exportador. Gourlay y Seaton (2004) observaron que el tamaño de la empresa, la innovación o el capital humano eran atributos esenciales para entrar en los mercados de exportación. En la misma dirección, Kamakura et al. (2012) concluyen que los factores clave para el desarrollo internacional de una empresa son el capital humano, la tecnología y las relaciones gerenciales.

Javalgi, White y Lee (2000) observaron la importancia de incluir características ligadas a la gestión para predecir con mayor precisión el comportamiento exportador. También concluyen que la contribución de las características de cada empresa a la propensión a exportar varía según la industria. En esta línea, Kalinic y Forza (2012) concluyen que el aspecto determinante del éxito en el cambio del proceso de internacionalización de las pymes tradicionales se basa en poseer un enfoque estratégico específico.

Los diferentes trabajos en este ámbito también han tratado la vertiente del apoyo institucional. Así, Westhead, White y Ucbasaran (2004) justificaron que las autoridades de política económica tienen mejores expectativas de éxito animando a las empresas ya exportadoras a redoblar sus esfuerzos en este ámbito, en vez de apoyando el incremento de empresas potencialmente exportadoras. 


\section{METODOLOGÍA}

En esta investigación ${ }^{1}$ se utiliza la base de datos ARDAN. Contiene datos de las empresas de la Comunidad Autónoma de Galicia. Con relación al concepto de pyme, la Comisión Europea discrimina entre pymes y grandes empresas considerando, entre otros criterios, un número de empleados menor de 250. Sin embargo, la cifra de empleados que se suele considerar fuera de Europa es de 500 (Lu y Beamish, 2004; Majochi et al., 2015). Por ello, este estudio ha optado por recoger el conjunto de las empresas gallegas que cuentan con menos de 500 empleados.

El rendimiento o actuación de la empresa se puede recoger a partir de distintas medidas: la cifra de ventas (Gourlay y Seaton, 2004), la ratio de rentabilidad sobre ventas (Contractor et al., 2003, Boehe et al., 2016), la Q de Tobin (Pantzalis, 2001), la rentabilidad económica y la rentabilidad financiera (Lu y Beamish, 2004; Thomas y Eden, 2004; Annavarjula y Beldona, 2005; Majochi et al., 2015). Se ha optado por utilizar la rentabilidad económica debido a la frecuencia de su uso.

Después de realizar un análisis descriptivo básico sobre la exportación en el ámbito geográfico del estudio, se analiza la estructura de dependencia existente entre la variable rentabilidad y diversos factores y variables cuantitativas. Los factores estudiados son el sector de actividad económica, la localización de la empresa, el año y el carácter exportador.

Posteriormente se realiza un análisis de la varianza para descubrir cuáles son los factores que provocan cambios en el valor de la rentabilidad económica. Se evalúa si el efecto del sector económico y la localización de la empresa influyen significativamente en la respuesta (rentabilidad). Como última etapa, se utiliza una regresión lineal múltiple para averiguar en qué medida el sector de actividad, número de empleados, facturación, localización, exportación, tiempo y $\mathrm{PIB}^{2}$.

\footnotetext{
${ }^{1}$ Incluye la evolución de más de 10.000 empresas durante el período de referencia.

${ }^{2}$ Datos obtenidos a partir del Instituto Nacional de Estadística (INE).
} 


\section{RESULTADOS}

Las provincias de A Coruña y Pontevedra son las que cuentan con más empresas, independientemente del sector, dentro de la Comunidad Autónoma de Galicia. Los sectores más representativos son la agricultura, construcción, detallistas, fabricantes, mayoristas y servicios. El porcentaje de empresas exportadoras está en torno al 10\% del total de pymes estudiadas. A partir del Gráfico $\mathrm{n}^{\circ} 1 \mathrm{y} \mathrm{n}^{\circ} 2$ se puede observar el número de pymes exportadoras a nivel sectorial, siendo mayor en el sector de fabricantes y mayoristas.

Para este análisis, se parte de una base de datos reducida. Se han eliminado aquellas observaciones de la rentabilidad detectadas como atípicos, es decir, mayores que Q3+1.5(Q3-Q1) y menores que Q11.5(Q3-Q1). La inclusión de empresas con rentabilidades extremadamente altas o bajas impediría, para las empresas más características de la población, analizar convenientemente la estructura de dependencia de esta variable con respecto a las demás.

A partir de los histogramas de las rentabilidades de las pymes gallegas para cada año, exportadoras o no, se observa el efecto de la crisis a partir de 2008. La cola derecha de los histogramas, que caracteriza a la proporción de compañías con una rentabilidad elevada, es cada vez menor. Sin embargo, el área bajo la cola izquierda se incrementa. El eje de simetría de los histogramas se desplaza, con independencia de su carácter exportador, hacia rentabilidades menores.

Si comparamos las funciones de densidad, estimadas mediante el método kernel gausiano y ventana óptima obtenida por el método de Seather y Jones (Venables y Ripley, 2002), se observan muy ligeras diferencias entre las empresas que exportan y las que no lo hacen. La probabilidad de que la empresa tenga una rentabilidad media, entre cuatro y cinco, es ligeramente superior en las empresas exportadoras. 


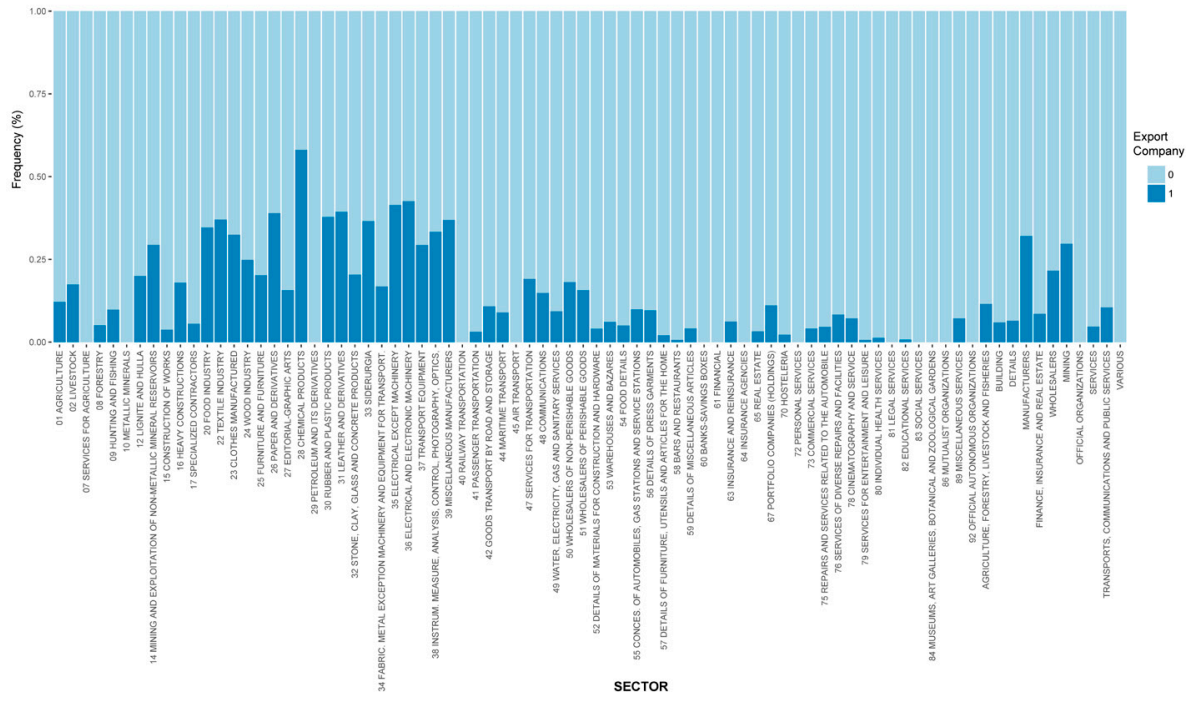

Gráfico 1. Pymes exportadoras por sector.

Fuente: elaboración propia a partir de ARDAN.

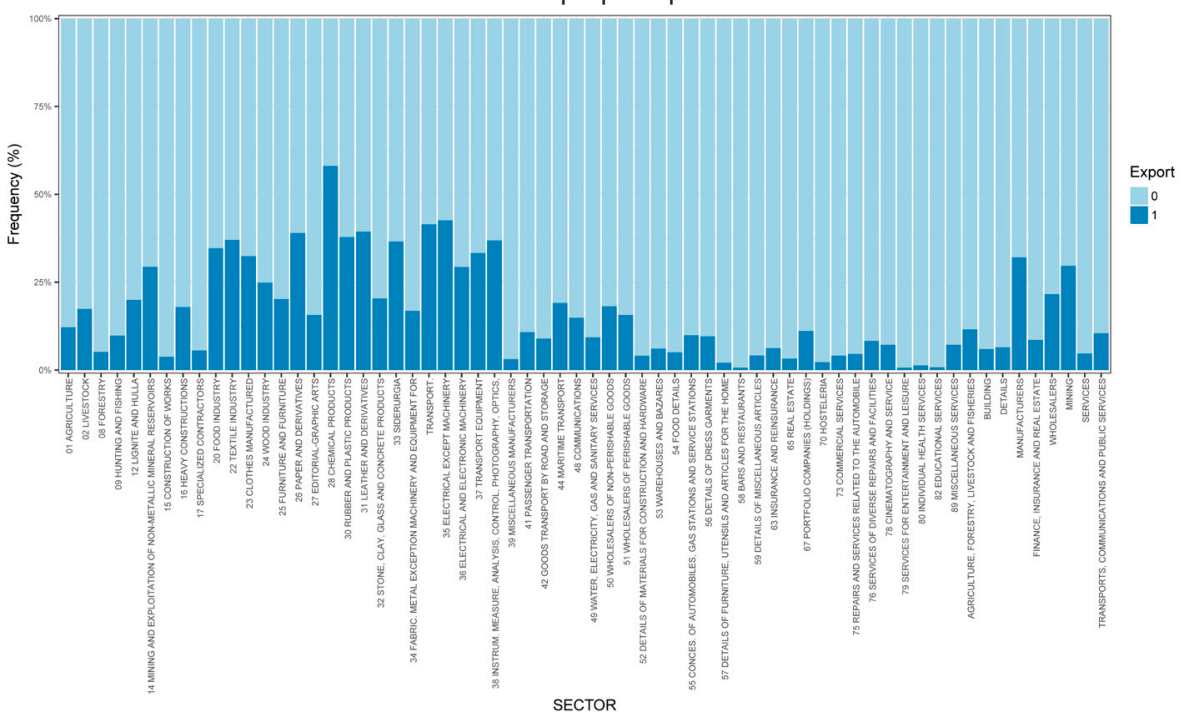

Gráfico 2. Sectores con Pymes exportadoras.

Fuente: elaboración propia a partir de ARDAN. 
Así, con anterioridad a la crisis, las compañías que exportaban tenían una mayor rentabilidad media. Durante los primeros años de la crisis, y hasta el año 2011, se ha observado que la rentabilidad de las empresas exportadoras fue ligeramente menor. La rentabilidad cayó desde seis a menos de 3,5 durante los peores años de la crisis. Ese año la rentabilidad de ambos tipos de empresas converge. Con posterioridad a 2012 se observa una tendencia ascendente, donde las empresas exportadoras presentan una rentabilidad media más elevada, aunque siempre teniendo en cuenta que las diferencias son muy escasas.

A partir de lo comentado anteriormente, el hecho de que una empresa exporte o no, podría afectar, aunque solo fuera muy ligeramente, a su rentabilidad. Igualmente, puede decirse del año (efecto de la crisis). Así, nos surge la pregunta ¿qué factores pueden provocar cambios significativos en el valor de la rentabilidad?

Todos los factores, salvo la exportación, influyen significativamente en el valor de la rentabilidad.

A partir de la aplicación del test $\mathrm{F}$, donde la hipótesis nula que se contrasta es que la media de la rentabilidad es igual para cualquier nivel de año, exportación, localización o sector (utilizado un p-valor de 0.05), se concluye que todos los factores, salvo la exportación, influyen significativamente en el valor de la rentabilidad. Sin embargo, si en lugar de estudiar los efectos principales, se estudian también las interacciones entre factores, se obtiene un resultado complementario indicando que el hecho de exportar si influye en el valor de la rentabilidad.

La interacción entre año y exportación provoca cambios significativos en la rentabilidad y es diferente según el año. Antes de la crisis el efecto de la exportación se traducía en un incremento de la rentabilidad. Durante los primeros años de la crisis afectaba negativamente a la rentabilidad y, posteriormente, positivamente de nuevo.

El modelo obtenido del análisis mediante la regresión líneal múltiple fue el siguiente:

$$
\begin{gathered}
\text { ROA }=\text { Sector }+ \text { Exportación }+1,61 * 10^{-3} \text { Empleo }+1,04 * 10^{-8} \text { Facturación }+ \text { Localización }- \\
0,21 \text { Tiempo }+3,28 * 10^{-6} \text { PIB }
\end{gathered}
$$

Se obtuvo como resultado de esta modelización que la relación entre la rentabilidad y el resto de variables es muy débil. Aunque se comprueba que existe una dependencia estadísticamente 
significativa, el modelo lineal resultante no proporcionaría estimaciones fiables de la rentabilidad para una nueva empresa.

Aumentos en el PIB, el número de empleados y la facturación se relacionan con incrementos en la rentabilidad, aunque la evolución en el tiempo se corresponde con un decremento en la misma.

Se observa que aumentos en el PIB, el número de empleados y la facturación están relacionados con incrementos en la rentabilidad. Por el contrario, la evolución en el tiempo se corresponde con un decremento en la rentabilidad. 


\section{CONCLUSIONES}

El primer hecho relevante que se desprende de este trabajo es que las empresas que exportan representan un porcentaje muy pequeño de la muestra, una décima parte. Así, el grado de internacionalización empresarial de la región estudiada es escaso. Además, también es destacable que las rentabilidades que presentan las empresas exportadoras son muy similares a las que no presentan ninguna actividad internacional.

Se observa una conducta ligada al ciclo económico y a la influencia del tiempo. Las firmas que ostentaban un enfoque internacional antes de la crisis presentaban una mayor rentabilidad media.

La influencia de la exportación sobre la rentabilidad revela la necesidad de ahondar en las consecuencias que tiene la primera sobre la gestión empresarial.

El análisis ha puesto de manifiesto qué, a excepción de la exportación, el resto de factores incluidos para explicar la rentabilidad empresarial influyen en ella significativamente. Sin embargo, si observamos las interacciones entre los factores, la exportación sí que influye sobre la rentabilidad. Este hecho revela la necesidad de ahondar en las consecuencias que tiene la exportación sobre la gestión empresarial.

La modelización propuesta, a través de una regresión lineal, no ha obtenido estimaciones fiables. Esto inicia el camino tanto a la utilización de nuevas variables explicativas como a utilizar otro tipo de modelos (por ejemplo, SVM o redes neuronales). El estudio de la propensión a exportar es otra cuestión ampliamente tratada en la literatura y una evolución natural de este trabajo. De este modo, se abre la posibilidad de emplear modelos logit o similares.

Asimismo, después de observar la distribución sectorial de las empresas exportadoras, se muestra interesante analizar estos sectores específicos. Al mismo tiempo, y dada la distribución espacial de las empresas a lo largo del territorio, enfocarse a subniveles geográficos específicos también es un ámbito relevante para ser explorado. 


\section{REFERENCIAS BIBLIOGRÁFICAS}

Annavarjula, M., y Beldona, S. (2000). Multinationality-performance relationship: a review and reconceptualization. International Fournal of Organizational Analysis, 8(1), 48-67.

ARDAN. (Varios años). Base de datos ARDAN. Vigo: Consorcio de la Zona Franca de Vigo. Departamento de servicios avanzados - ARDAN.

Bernard, A. B., y Jensen, J. B. (1999). Exceptional exporter performance: Cause, effect, or both? Journal of International Economics, 47(1), 1-25.

Boehe, D. M., Qian, G., y Peng, M.W. (2016). Export intensity, scope and destinations: Evidence from Brazil. Industrial Marketing Management, 57, 127-138.

Contractor, F. J., Kundu, S.K., y Hsu, G-C. (2003). A three-stage theory of international expansion: the link between multinationality and performance in the service sector. Fournal of International Business Studies, 34, 5-18.

Ellis, P.D., Davies, H., y Wong, A. H-K. (2011). Export intensity and marketing in transition economies: Evidence from China. Industrial Marketing Management, 40(4), 593-602.

Giovannetti, G., Ricchiuti, G. y Velucchi, M. (2013). Location, internationalization and performance of firms in Italy: a multilevel approach. Applied Economics, 45, 2665-2673.

Glaum, M., y Oesterle, M.J. (2007). 40 years of research on internationalization and firm performance: More questions than answers? Management International Review, 47(3), 307-317.

Gomes, L., y Ramaswamy, K. (1999). An empirical examination of the form of the relationship between multinationality and performance. Fournal of International Business Studies, 30, 173188.

Gourlay, A., y Seaton, J. (2004). Explaining the decision to export: evidence from UK firms. Applied Economics Letters, 11, 153-158.

INE. (Varios años). Contabilidad Nacional anual de España. Madrid: Instituto Nacional de Estadística. Recuperado de: http://www.ine.es/dyngs/INEbase/es/operacion. htm?c=Estadistica_C\&cid $=1254736165950 \&$ menu $=u l t i D a t o s \& i d p=1254735576581$ 
Javalgi, R., White, D.S. y Lee, O. (2000). Firm characteristics influencing export propensity: An empirical investigation by industry type. Fournal of Business Research, 47, 217-228.

Johanson, J. y Vahlne, J.E. (1977). The internationalization process of the firm - a model of knowledge development and increasing foreign market commitment. Fournal of International Business Studies, 8(1), 23-32.

Kalinic, I., y Forza, C. (2012). Rapid internationalization of traditional SMEs: Between gradualist models and born globals. International Business Review, 21(4), 694-707.

Kamakura, W.A., Ramón-Jerónimo, M.A., y Vecino Gravel, J.D. (2012). A dynamic perspective to the internationalization of small-medium enterprises. Fournal of the Academy Marketing Science, 40, 236-251.

Li, L. (2007). Multinationality and performance: A synthetic review and research agenda. International Journal of Management Reviews, 9(2), 117-139.

Li, L., y Qian, G. (2005). Dimensions of international diversification: the joint effects on firm performance. Fournal of Global Marketing, 18(3/4), 7-35.

Ling-Yee, L. (2004). An examination of the foreign market knowledge of exporting firms based in the People's Republic of China: Its determinants and effect on export intensity. Industrial Marketing Management fournal, 22(6/7), 656-586.

Lu, J.W., y Beamish, P.W. (2004). International diversification and firm performance: the S-curve hypothesis. Academy of Management fournal, 47, 598-609.

Majocchi, A., Dalla Valle, L., y D’Angelo, A. (2015). Internationalisation, cultural distance and country characteristics: A bayesian analysis of SMEs financial performance. Fournal of Business Economics and Management, 16(2), 307-324.

Oviatt, B.M. y McDougall, P.P. (1994). Towards a theory of international new ventures. Fournal of International Business Studies, 25(1), 45-64.

Pangakar, N. (2008). Internationalization and performance of small-and medium-sized enterprises. Journal of World Business, 43, 475-485. 
Pantzalis, C. (2001). Does location matter? An empirical analysis of geographic scope and MNC market evaluation. Fournal of International Business Studies, 32, 133-155.

Ramírez-Aleson, M., y Espitia-Escuer, M.A. (2001). The effect of international diversification on performance. Management International Review, 41, 291-315.

Serra, F., Pointon, J., y Abdou, H. (2012). Factors influencing the propensity to export: a study of UK and Portuguese textile firms. International Business Review, 21, 210-224.

Serti, F., y Tomasi, Gh. (2014). Export and import market-specific characteristics. Empirical Economics, 47, 1467- 1496.

Venables, W. N., y Ripley B. D. (2002). Modern Applied Statistics with S. Springer.

Westhead, P., Wright, M., y Ucbasaran, D. (2001). The internationalization of new and small firms: A resource-based view. Fournal of Business Venturing, 16(4), 333-358.

Yi, J. y Wang Ch. (2012). The decision to export: Firm heterogeneity, sunk costs, and spatial concentration The decision to export: Firm heterogeneity, sunk costs, and spatial concentration. International Business Review, 21, 766-781. 


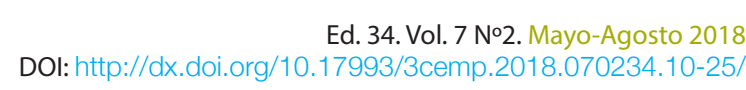


/02/ 


\section{Mujeres rurales emprendedoras, detonadoras de desarrollo económico: binomio colaboración - empoderamiento}

Entrepreneurial rural women, economic development detoners: binding collaboration - empowerment

Isabel Pérez Pérez

Docente/Investigadora

Titular de la Escuela de Ciencias Administrativas Istmo Costa, Campus IX, Tonalá. Universidad Autónoma de Chiapas. Investigadora Nacional Nivel 1 Investigadora Estatal Honoraria Nivel VI. Perfil Prodep. isabelperez1491@hotmail.com

Recepción: 05/01/2017. Aceptación: 21/02/2017. Publicación: 24/05/2018

Citación sugerida:

Pérez Pérez, I. (2018). Mujeres rurales emprendedoras, detonadoras de desarrollo económico: binomio colaboración - empoderamiento. 3C Empresa: investigación y pensamiento crítico, 7(2), 26-43. DOI: http://dx.doi. org/10.17993/3cemp.2018.070234.26-43/ 


\section{RESUMEN}

La mujer rural emprendedora es factor clave de la sociedad mexicana que genera recursos económicos a las familias. En Chiapas (México), no se pueden excluir de la situación específica de las mujeres rurales, las cuales representan el 50,4\% del total de las mujeres mexicanas (CEAMEG, 2014). La mayoría de este colectivo, están en situación de pobreza extrema. Además de vivir en comunidades rurales, con una inadecuada infraestructura de servicios, escasos servicios de salud o educativos, y con necesidades básicas insatisfechas en la mayoría de los hogares, viven dominadas por el sistema "machista" propia de una cultura rural, sin reconocimiento de sus derechos, ni de sus labores dentro y fuera del hogar.

Por ello, se presenta este estudio que se realizó con una metodología mixta, cualitativa y cuantitativa. La recolección de información utilizó los siguientes instrumentos metodológicos: un grupo focal y la aplicación de una encuesta semi estructurada a los participantes del mismo grupo focal (hombres, mujeres y jóvenes, todos ellos mayores de 18 años, vendedores de pescado en la periferia del mercado público Manuel Larrainzar). El resultado reflejó que de las 17 personas que comercializan su producto en este sitio, 15 son mujeres, y únicamente 2 hombres; de ellos, 10 son casados (as), 3 solteras, 1 que vive en unión libre, 1 madre soltera, 1 divorciada y 1 viuda, como se puede observar el rol protagónico de la mujer en esta actividad comercial es predominante.

\section{ABSTRACT}

Rural women entrepreneurs is key factor in Mexican society that generates income to families. In Chiapas (Mexico), may not be excluded from the specific situation of rural women, which account for 50.4 per cent of the total of Mexican women (CEAMEG, 2014). The majority of this group, are in extreme poverty. In addition to live in communities that are rural, with inadequate infrastructure services, scarce health services or educational, and basic needs unmet in most households, they live dominated by the "macho" system of a rural culture, without recognition of their rights, or their work inside and outside the home.

Why is this study which was carried out with a joint, qualitative and quantitative methodology. The collection of information used the following methodological instruments: implementation of a survey and a focus group semi structured to participants of the same target group (men, women and young people, all of them older than 18 years, fish sellers in the periphery of the public market Manuel Larrainzar). The result reflected that of the 17 people who marketyour product on this site, 15 are women, and only 2 men; of them, 10 are married (as), 3 single and 1 who lives in free union, 1 single mother, divorced 1 and 1 widow, as you can see the role of women in this commercial activity is predominant. 


\section{PALABRAS CLAVE}

Mujeres rurales, Mercados públicos, Empoderamiento, Economía.

\section{KEY WORDS}

Rural women, Public markets, Empowerment, Economy. 


\section{INTRODUCCIÓN}

Con este estudio se logró identificar la problemática que viven las mujeres emprendedoras rurales que vienen a la ciudad a buscar un sitio en los mercados locales para la venta de su producto (pescado) y tienen que ubicarse en la periferia del mercado público, puesto que no tienen un sitio definido para realizar la comercialización de su mercancía. Considerando que estos lugares ofrecen una serie de oportunidades para vendedores y compradores de distintos tipos de productos y servicios.

Por ello, primeramente se elaboró un censo que permitió obtener datos e información para posteriormente proponerles una forma de organización que les facilite realizar esta actividad de forma más segura y puedan obtener ganancias que les provea para que puedan vivir de una manera digna.

En segundo lugar, se ubicaron los problemas a que se enfrentan en el día a día, estas mujeres para realizar sus actividades diarias en una matriz FODA. Posteriormente, se les diseñaron documentos contables donde podrán llevar un registro que concentre todas sus operaciones diarias como son sus compras y ventas, así como lo que se invierte y cuanto se obtiene de ingreso económico al efectuar la comercialización de su producto, si se obtiene una ganancia o no.

Considerando que los mercados públicos proveen grandes oportunidades de negocio, para los que ofrecen productos o servicios por representar un sitio donde oferentes y demandantes convergen para buscar mejores oportunidades, tanto en los precios, como en las oportunidades de ventas comerciales.

\subsection{CARACTERÍSTICAS DE LA POBLACIÓN OBJETO DE ESTUDIO}

En las comunidades rurales, existen muy pocas actividades que pueda absorber la mano de obra femenina, lo que implica que las mujeres en edad productiva genere su propio empleo, por medio de la venta y comercialización de todos aquellos productos o servicios que impliquen una oportunidad de trabajo, que les provea ingresos mínimos necesarios para su subsistencia y la de su familia.

Un ejemplo, es el que realizan las mujeres rurales emprendedoras que venden pescado en la periferia del mercado público Manuel Larrainzar, ubicado en Tonalá, Chiapas. La importancia de esta actividad radica en la cadena de valor que genera este proceso de compra/venta para las comunidades, aun cuando no se considera un trabajo formal, es una ocupación digna. 
Observándose que la situación económica de estas personas, no está tan deprimida como en otras familias que no realizan actividades de comercialización y que dependen únicamente de los apoyos gubernamentales que mes a mes reciben. Este es un factor muy importante si se considera que los hijos, principalmente mujeres, forman parte de la fuerza de trabajo en esta actividad (Pérez, Orozco \& Cruz, 2014).

\section{La situación económica de las mujeres rurales que venden pescado no está tan deprimida como en otras familias que no realizan actividades de comercialización y que dependen de los apoyos gubernamentales.}

Según García (2003), el trabajo manual es significativo por el hecho de no contar con tecnología, estructura un proceso de trabajo diferente al de una organización industrial con producción en serie. La producción está orientada hasta ahora, a la generación de un ingreso familiar de subsistencia (ver figuras 1,2 y 3$)$.

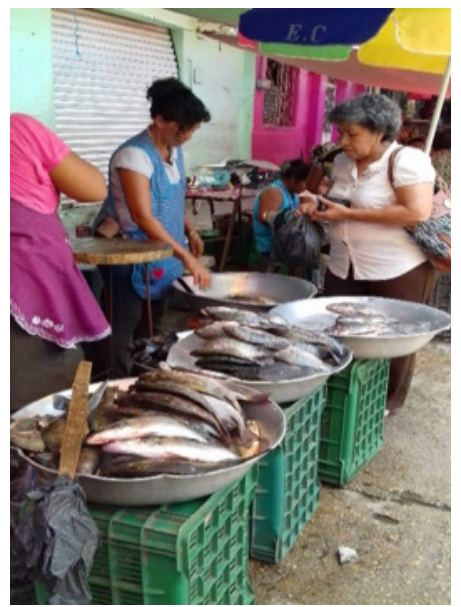

Figura 1. Mujeres rurales vendedoras de pescado en el mercado público Manuel Larrainzar en Tonalá, Chiapas. 


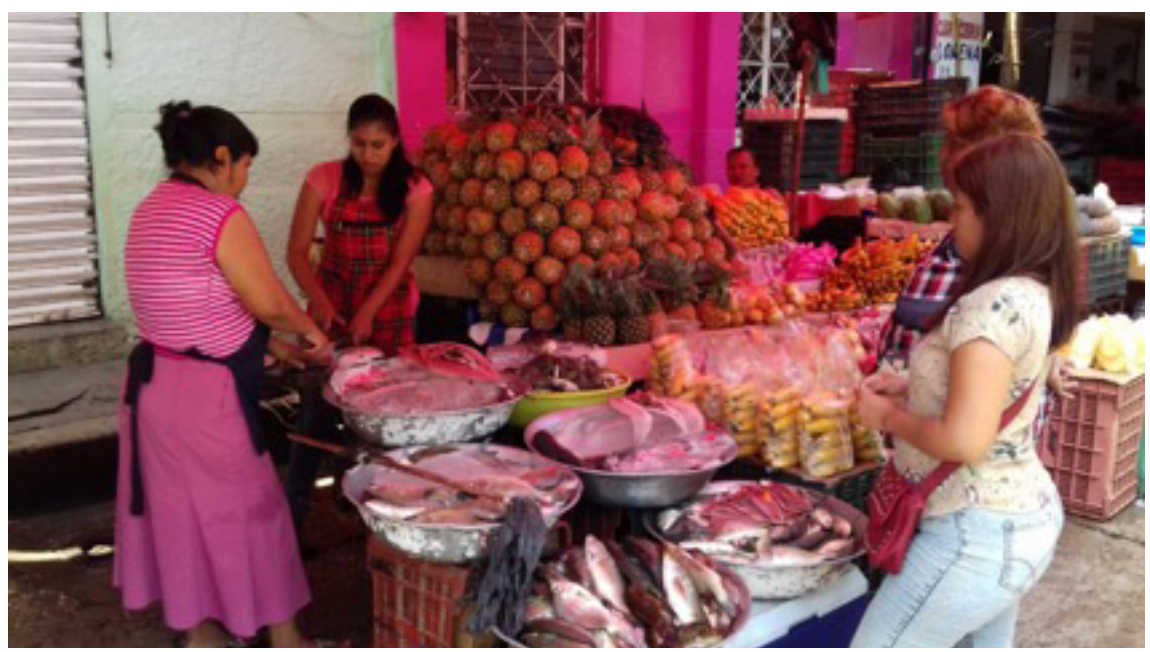

Figura 2. Mujeres rurales vendedoras de pescado en el mercado público Manuel Larrainzar en Tonalá, Chiapas.

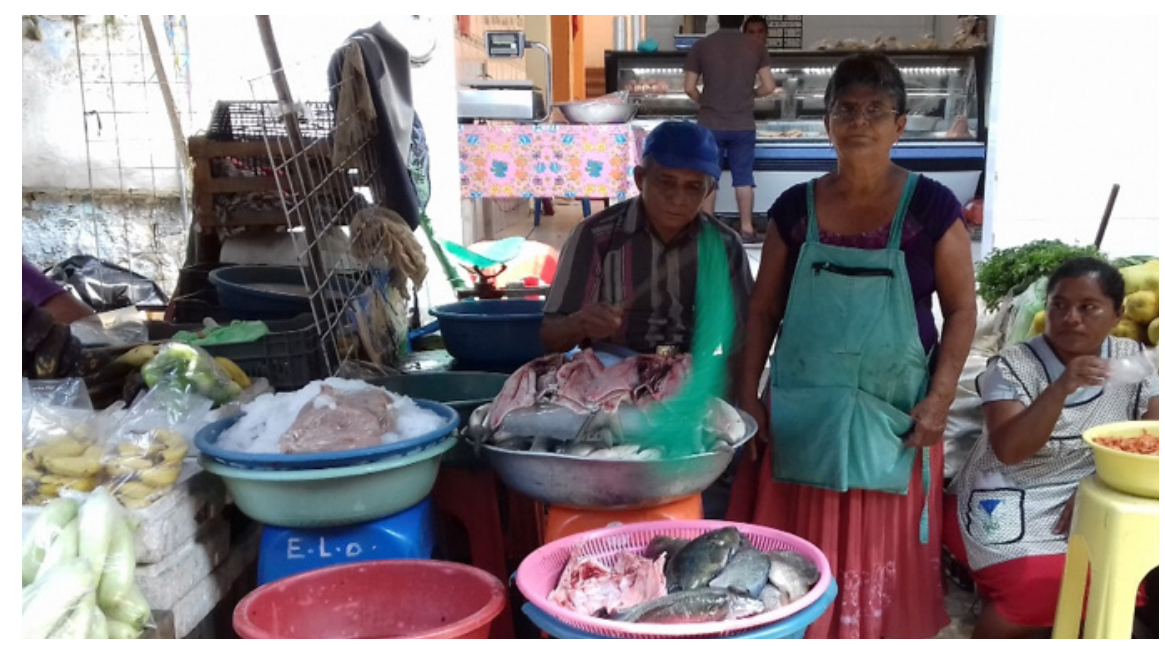

Figura 3. Mujeres rurales vendedoras de pescado en el mercado público Manuel Larrainzar en Tonalá, Chiapas. 


\subsection{SITUACIÓN DE LAS MUJERES RURALES EN CHIAPAS (MÉXICO)}

En 2010, la población que vivía en localidades rurales (menos de 2,500 habitantes) sumaba 26 millones y representaba 23.2 por ciento de la población total del país; alrededor de 13.4 millones son mujeres y 12.9 millones son hombres. La edad mediana de las mujeres rurales es de 23 años y 22 para los hombres, mientras que la correspondiente a las mujeres de grandes ciudades de 100 mil y más habitantes es 29 años, 2 más que los hombres cuya edad mediana es de 27 años (CEAMEG con base en INEGI Estadísticas históricas de México 2009).

En este mismo año, CEAMEG menciona, que había 102 mujeres rurales por cada 100 hombres rurales. Oaxaca es la entidad federativa que tiene una mayor proporción de mujeres rurales $(52.3 \%)$, seguida de Chiapas con la mitad de su población de mujeres residentes en áreas rurales. Hidalgo y Tabasco también tienen una importante proporción de mujeres rurales, 47.4 y 41.9 por ciento, respectivamente.

\section{Las mujeres rurales representan el 504\% del total de mujeres mexicanas.}

Por lo tanto, las mujeres en Chiapas, no se pueden excluir de la situación específica de las mujeres rurales, las cuales representan el 50,4\% del total de las mujeres mexicanas (CEAMEG, 2014). La mayoría de este colectivo, están en situación de pobreza extrema. Además de vivir en comunidades rurales, con una inadecuada infraestructura de servicios, escasos servicios de salud o educativos, y con necesidades básicas insatisfechas en la mayoría de los hogares, viven dominadas por el sistema "machista" propia de una cultura rural, sin reconocimiento de sus derechos, ni de sus labores dentro y fuera del hogar.

Esto limita su integración y participación en actividades comunitarias, o llegar a ser parte de organizaciones donde se toman decisiones relacionadas con el desarrollo. Según Mareswara (2016), las responsabilidades asumidas en función de su sexo (cuidado de la familia, tareas domésticas, cuidado de animales de traspatio, etc.) y otras referidas a las tareas agrícolas reducen sus posibilidades de tener una actividad económica que les genere ingresos para su autonomía, o bien actividades relacionadas con su desarrollo personal que le permita elevar su autoestima.

Deben sobrevivir en un sistema que les ha negado el acceso a recursos productivos, asistencia técnica, 
conocimientos y formas de organización propias. Conscientes de este problema, las instituciones públicas del país han comenzado a abordar el problema y promover los derechos de las mujeres a nivel legislativo y estratégico (CEAMEG, 2014).

Para ello se han elaborado documentos básicos en materia de derechos humanos de las mujeres como: la "Convención sobre la eliminación de todas las formas de discriminación contra la Mujer", aprobada por la ONU en 1979 a nivel internacional, y a nivel regional, la "Convención interamericana para prevenir, sancionar y erradicar la violencia contra la mujer" conocida como Convención de Belém de Pará desde 1999; a nivel nacional, el Congreso de la Unión aprobó en febrero del 2007 la "Ley General de acceso de las mujeres a una vida libre de violencia".

En términos generales se puede decir que el país cuenta con un amplio marco jurídico que protege algunos de los derechos básicos de las mujeres (ver Cuadro No. 1: Derechos Humanos de las mujeres). Sin embargo, aún queda mucho trabajo por realizar para romper con el estigma de la exclusión que pesa sobre las mujeres, principalmente rurales, y que no las reconocen como parte fundamental del desarrollo del país, mucho menos del estado, municipio o comunidad.

Tabla 1. Derechos Humanos de las Mujeres.

\begin{tabular}{|l|c|}
\hline \multicolumn{1}{|c|}{ ACCIÓN } & AÑO \\
\hline Se crea la Comisión de Equidad y Género en la Cámara de Diputados & 1999 \\
\hline Se crea la Ley del Instituto Nacional de las Mujeres & 2001 \\
\hline Se promulga la Ley Federal para Prevenir y Eliminar la Discriminación & 2003 \\
\hline $\begin{array}{l}\text { Se promulga la Ley General para la Igualdad entre Mujeres y Hombres } \\
\text { Se promulga la Ley General de Acceso de las Mujeres a una vida Libre de Violencia. }\end{array}$ & 2006 \\
\hline $\begin{array}{l}\text { Se promulga la Ley para Prevenir y Sancionar la Trata de Personas. } \\
\text { Se tipifica el feminicidio en el Código Penal Federal. }\end{array}$ & 2007 \\
\hline $\begin{array}{l}\text { Ley General de Instituciones y Procedimientos Electorales, la obligación para los partidos políticos de asegurar la } \\
\text { igualdad de oportunidades y la paridad entre hombres y mujeres para tener acceso a cargos de elección popular. }\end{array}$ & 2007 \\
\hline Ley General sobre los Derechos de Niñas, Niños y Adolescentes. & 2012 \\
\hline
\end{tabular}

Fuente: CEAMEG a partir de la Cámara de Diputados 2016. 


\subsection{JUSTIFICACIÓN}

La idea de promover el empoderamiento de las mujeres constituye parte de un cambio cultural, social y económico, entendido como un proceso orientado de forma consciente a transformar ideas, creencias y conductas que afectan la calidad de vida de hombres y mujeres; incluso, el desarrollo de las comunidades rurales (Villarreal, 2011).

Para que la voluntad de modificar el sometimiento de género por el empoderamiento sea efectivo, se debe involucrar a las partes para percibir si desean cambiar y como se debe participar en ese proceso de cambio que se pretende lograr (Narasimha, Anand, Ravish, Navya y Ranganath, 2016). Si no existe el deseo de colaboración entre este colectivo (hombres y mujeres), difícilmente se conseguirá este cambio esperado. Para ello, fue necesario analizar sus costumbres, usos, prácticas, tradiciones e ideas que prevalece en las comunidades rurales con respecto al rol de género.

Por tal motivo, el empoderamiento reconoce la necesidad de aumentar el poder de las mujeres, definido en términos de liderazgo que les permitirá influir en el cambio cultural, económico, político y social a través del control de recursos materiales y no materiales (Hidalgo, 1999).

Pérez, Vázquez \& Zapata (2008) explican que "Género en Desarrollo", considera a las mujeres como sujetos dinámicos y promotores de cambios, por lo que, propone el empoderamiento femenino, como estrategia para superar las limitaciones de lo mencionado ‘por las "Mujeres en Desarrollo". Para Young (1997), el empoderamiento consiste en facilitar el control de las mujeres sobre los procesos que afectan sus vidas, lo que les permitirá vigilar sus propias actividades, organizarse para ayudarse unas a otras y generar peticiones de apoyo a las instancias locales, municipales, estatales y nacionales para incidir en el cambio, desarrollo de la sociedad, del país y del mundo.

La perspectiva de Género en Desarrollo, se ocupa de las relaciones de género en situaciones culturales e históricas concretas. Incluye, en la agenda para el cambio, las necesidades estratégicas de las mujeres, buscando modificar relaciones de desigualdad (Nazar \& Zapata, 2000).

Pérez et al., (2008) continúa comentando las afirmaciones de Género en Desarrollo y analizan el papel de éste colectivo en el ámbito productivo, con el fin de que la política pública no genere nuevas cargas de trabajo para ellas. En su propuesta introduce dimensiones cualitativas, quizá no medibles, del desarrollo, como por ejemplo la importancia de la autonomía femenina, de su independencia económica, de su desarrollo emocional y profesional, así como la necesidad de promover una 
democracia participativa donde la brecha entre líderes e instituciones sea eliminada para que las personas sean sujetos modificadores de sus propios entornos (Pérez, 2001).

Según Rowlands (1997), a partir de la investigación que hizo en grupos de mujeres rurales, el empoderamiento de estas es "un núcleo de procesos psicológicos que cuando se desarrollan, capacitan al individuo o al grupo para actuar de tal forma que incremente su acceso al poder y su uso en varias formas". Eso significa la capacidad para elevar su conciencia como mujeres y el desarrollo de habilidades para superar problemas y encontrar salidas y soluciones.

Villarreal, (2011), comenta del estudio anterior, parecería, “con los datos registrados sobre el número de mujeres que están participando en los mercados públicos, que las mujeres están encontrando caminos para incrementar su participación en las ventas de manera autónoma", lo que sería una pista sobre su avance en términos de empoderamiento. 


\section{METODOLOGÍA}

El diseño de la investigación es de tipo cualitativo y descriptivo, se desarrolló en dos fases para que se capturaran los distintos significados de este fenómeno social y personajes involucrados en este proceso; el problema a estudiar fue el binomio colaboración empoderamiento femenino de las vendedoras de pescado en la periferia del mercado público Manuel Larrainzar en Tonalá, Chiapas. En la primera fase, se llevó a cabo por medio de la observación y el análisis de los testimonios recogidos con el grupo de enfoque realizado, se fue construyendo su significado de acuerdo a los comentarios, opiniones, ideas vivencias y sentimiento de este colectivo (ver Cuadro No. 2: Censo de mujeres vendedoras de pescado).

La información recogida con esta metodología, fue llevada a cabo durante los meses de junio a diciembre del año 2016. A partir de la identificación de las dificultades se construyó una matriz FODA que se utilizó para visualizar una síntesis del binomio colaboración-empoderamiento por parte de las mujeres rurales emprendedoras; iniciando de forma individual y concluyendo de manera colectiva (Tabla 3 ).

Tabla 2. Censo de mujeres vendedoras de pescado.

\begin{tabular}{|l|l|l|l|}
\hline \multicolumn{1}{|c|}{ NOMBRES } & \multicolumn{1}{c|}{ EDAD } & \multicolumn{1}{c|}{ EDO. CIVIL } & HIJOS \\
\hline Nicolasa Trinidad Castañeda & 42 & Casada & 6 \\
\hline Margarita Trinidad Castañeda & 49 & Casada & 8 \\
\hline Teresa de Jesús Matías Trinidad & 30 & Casada & 4 \\
\hline Guadalupe Salazar Mendoza & 40 & Divorciada & 3 \\
\hline Danny Gricel Natarán Roblero & 23 & Soltera & 0 \\
\hline Rosa Alba Lorenzana Ramos & 40 & Casada & 3 \\
\hline Gloria Trujillo & 41 & Viuda & 5 \\
\hline Sandra luz Cigarroa Flores & 38 & Casada & 1 \\
\hline Elidía López Ovando & 67 & Casada & 6 \\
\hline Elio Cueto De los Santos & 68 & Casado & 6 \\
\hline Margarito Matías Mateo & 52 & Casado & 8 \\
\hline Violeta López Caballero & 45 & Casada & 3 \\
\hline Leydi Ovando Ríos & 30 & Casada & 1 \\
\hline María angélica De Paz Trinidad & 23 & Soltera & 0 \\
\hline Graciela De Paz Trinidad & 22 & Soltera & 0 \\
\hline Mari Celia Matías Trinidad & 32 & Madre soltera & 1 \\
\hline Aloína Ovando Antonio & 55 & Unión Libre & 5 \\
\hline
\end{tabular}

Fuente: elaboración propia. 
Tabla 3. Binomio Colaboración-Empoderamiento.

\begin{tabular}{|c|c|c|}
\hline & FORTALEZAS & DEBILIDADES \\
\hline+ & $\begin{array}{l}\text { - Incorporación cada día más a la Educación } \\
\text { - Buscan alternativas de independencia } \\
\text { económica } \\
\text { - Mejoran cada día más su autoestima } \\
\text { - Valoran más su capacidad creativa } \\
\text { - Potencian su desarrollo personal } \\
\text { - Brindan más atención en aspectos de su } \\
\text { salud } \\
\text { - Apoyo mutuo para superarse } \\
\text { - Más información sobre la equidad de } \\
\text { género }\end{array}$ & $\begin{array}{l}\text { - Ausencia de capacitación en nuevas tecnologías } \\
\text { - Bajos conocimientos empresariales } \\
\text { - Falta de organización en los grupos de mujeres } \\
\text { - Carencia de autonomía en la Toma de Decisiones } \\
\text { - Escasez de herramientas de Mercadotecnia. } \\
\text { - Tienen que solicitar autorización para desplazarse } \\
\text { de un sitio a otro, } \\
\text { - Nulos conocimientos contables-administrativos } \\
\text { - Bajo nivel de estudios }\end{array}$ \\
\hline+ & $\begin{array}{l}\text { - Mejorar su calidad de vida } \\
\text { - Poseen mayor voluntad para emprender } \\
\text { - Desafían las leyes de subordinación } \\
\text { - Mayor capacidad de reacción ante los } \\
\text { problemas } \\
\text { - Han ido venciendo el miedo al cambio } \\
\text { - Se han decido a ser protagonistas de su } \\
\text { vida } \\
\text { - Son estupendas negociadoras }\end{array}$ & $\begin{array}{l}\text { - Opresión de parte de los hombres de su entorno } \\
\text { - Escasez de trato afectuoso por parte de sus } \\
\text { padres } \\
\text { - Falta de respeto en el hogar } \\
\text { - Ausencia de involucramiento de los esposos en } \\
\text { labores domésticas. } \\
\text { - Trato desigual hombre/mujer en el espacio familiar. } \\
\text { - Violencia verbal y maltrato familiar }\end{array}$ \\
\hline & OPORTUNIDADES & AMENAZAS \\
\hline
\end{tabular}

Fuente: elaboración propia.

Las mujeres asistentes, que se atrevieron a verbalizar las condiciones de inequidad, opinaron que con la venta de pescado en la periferia del mercado público, existe la posibilidad de mejorar su condición o al menos atenuar su impacto.

Una de ellas decía: "en la comercialización, veo otra perspectiva de vida, me da otra visión". En el grupo, se manifestó preocupación por la mejor manera de introducir cambios y de promover la solidaridad entre mujeres. Esta idea que se relaciona con las actoras sobre las "buenas costumbres" entre las mujeres, facilitarían los procesos organizativos para que pudieran darse apoyo mutuamente que beneficiaría su unidad, facilitando la transición a empoderarse.

También explicaron, que en las actividades de comercialización, que comprende la compra/ venta, es donde se produce la mayor utilidad, pues al realizarse la venta se da la valorización de la mercancía, es decir, se materializa el esfuerzo del trabajo en dinero, y se pueden calcular y comparar los costos de adquisición del producto, así como del valor agregado (ganancia). 


\section{RESULTADOS}

El análisis realizado reveló que de las 17 personas que comercializan su producto en este sitio, 15 son mujeres, y únicamente 2 hombres; de ellas 10 son casadas (os), 3 solteras, 1 que vive en unión libre, 1 madre soltera, 1 divorciada y 1 viuda, como se puede observar el rol protagónico de la mujer en esta actividad es predominante.

Estas mujeres tienen como apoyo económico ahorros propios, tandas, préstamo que solicitan a familiares y amigos, porque los sistemas crediticios o microcréditos les cobran demasiados intereses propiciando que no lo puedan pagar.

Con respecto a los ingresos que reciben por las ventas que realizan, se reflejó que las mujeres asumen más responsabilidades y compromisos que los hombres, puesto que después de haber cumplido con el total de sus ventas, el ingreso que obtienen de su negocio, un porcentaje es para comprar su mercancía al día siguiente; otra porción, para el pago de sus pasajes y traslados al lugar donde realizan su compra e ir al lugar donde está su expendio, incluso tienen que separar otro porcentaje para enviar a sus hijos a la escuela, otra fracción para el alimento diario de su familia.

Estas mujeres tienen como apoyo económico ahorros propios, tandas, préstamo que solicitan a familiares y amigos, porque los sistemas crediticios o microcréditos les cobran demasiados intereses propiciando que no lo puedan pagar. También reciben apoyos económicos estatales, cuya cantidad oscila entre 2 mil a 3 mil pesos como beca a sus hijos que están en la escuela. Esto les da un fuerte impulso económico, lo que les permite "refaccionarse" y tener efectivo para comprar su producto (pescado).

Habitualmente este negocio no necesita que las personas tengan gran experiencia en el trabajo, es suficiente que sepan "realar" el pescado, es decir, limpiarlos y abrirlos; preparándolos para darles la presentación que solicita el cliente, de acuerdo a como lo requieran en su hogar para su alimento (frito, en caldo, empanizado, al horno, asado, ceviche, al hervor, al agua chile, tapadito, empapelado etc.,). La forma de "comerciar" la van adquiriendo conforme pasa el tiempo y venden su mercancía (Pérez et al. 2014)

La edad de las vendedoras de pescado, fluctúa en un 60 por ciento de 30 a 50 años, otro porcentaje menor el 23 por ciento son mayores de 50 años y únicamente el 17 por ciento corresponden de 20 
a 29 años. En cuando a la edad de cuando iniciaron este negocio, la mitad de ellas comenzaron este comercio a la edad de 20 a 40 años y la otra mitad de las propietarias comenzaron este negocio a una edad de 20 años y menores de 20.

Al decir de ellas, la mayoría tuvo algo de planeación no escrita cuando empezó su negocio y solo la minoría hizo un plan de negocios, hay que aclarar cuando ellas hablan de planeación, es cuando van a preguntarle a sus familiares o amigos, acerca de poner un pequeño negocio, incluso, se llega al caso, que van y hablan con los dirigentes de sus sectas (las cuales hay muchas en estos lugares y de las que son integrantes). Este mismo caso pasa cuando hablamos de asesoría profesional, aunque la mayoría dijo que no tuvo asesoría profesional, se da mucho el caso anterior (Pérez et al. 2014).

Por lo tanto, se pudo observar que la educación es uno de los factores principales que afectan a la labor que realizan; otro factor no menos importante es el tiempo que le dedican a sus actividades comerciales, a menor tiempo, menor espacio empleado para su trabajo. Otro factor, son las razones personales y/o familiares, que las limita, tomando la preferencia de no ir más allá en su comercio. Generalmente estas propietarias tienen un nivel educativo máximo de primaria, algunas de ellas tienen secundaria y solo un grupo minoritario tienen preparatoria, actualmente dos de ella están estudiando licenciatura en Contaduría Pública lo que potenciará su conocimiento para llevar el registro de sus gastos y costos en su negocio. 


\section{CONCLUSIONES Y PROPUESTA DE MEJORA}

Poner fin a la pobreza en todas sus formas, también tiene una resonancia especial para las mujeres rurales. La interrelación entre el acceso limitado a los recursos, la educación y la atención médica inapropiadas, la discriminación sistemática y los obstáculos a su participación agravan su condición de pobreza y exclusión.

Por ello, el empoderamiento de las mujeres rurales, es un requisito previo para lograr la visión de los Objetivos de Desarrollo Sostenible 2030, que se propone "poner fin a la pobreza y el hambre, alcanzar la seguridad alimentaria y empoderar a todas las mujeres y las niñas como agentes clave en los sistemas alimentarios", tan prioritario para este colectivo que se encarga de garantizar la alimentación adecuada para las familias; las mujeres rurales se encuentran en el centro de este desafío.

Si se logra que el grupo de mujeres rurales emprendedoras que venden pescado en la periferia del mercado público Manuel Larrainzar se organicen para acceder a créditos, apoyos municipales, estatales y nacionales, además, se les proporcione una alternativa de distribución, así como dotarlas de herramientas estratégicas de mercadotecnia para que mejoren la comercialización, imagen e higiene de su producto, solo entonces se podrá garantizar que ellas alcanzarán su nivel de bienestar mínimo para satisfacer las necesidades económicas de su familia, hijos, padres, abuelos y todos aquellos que dependen de este colectivo.

El empoderamiento de las mujeres rurales, es un requisito previo para lograr la visión de los Objetivos de Desarrollo Sostenible 2030, que se propone "poner fin a la pobreza y el hambre, alcanzar la seguridad alimentaria y empoderar a todas las mujeres y las niñas como agentes clave en los sistemas alimentarios".

Finalmente, se debe involucrar a todos los integrantes de la familia a que participen activamente en las labores diarias del hogar, para propiciar que las mujeres descarguen sus quehaceres y responsabilidades, que les permita tener un horario de esparcimiento y relax para su bienestar emocional que repercutirá en el progreso de todos los miembros de la familia y ellas puedan lograr su pleno desarrollo personal y social que detone su mejoría económica y la de su entorno. 


\section{AGRADECIMIENTOS}

- Al COCYTECH por el apoyo económico proporcionado para la realización de este estudio.

- A las mujeres rurales emprendedoras que venden pescado en la periferia del Mercado público Manuel Larrainzar en Tonalá, Chiapas. "gracias por su participación".

\section{REFERENCIAS BIBLIOGRÁFICAS}

Centro de Estudios para el adelanto de las Mujeres y la Equidad de Género (GEAMEG). (2016). Las reformas a la Constitución de 1917 desde el punto de vista de las mujeres. Cámara de Diputados LXIII Legislatura. México, D.F.

García Canclini, N. (2003). Culturas hibridas. Estrategias para entrar y salir de la modernidad. Editorial Grijalbo, México, D. F.

Hidalgo, C.N. (1999). Cajas de ahorro como estrategia de sobrevivencia de mujeres rurales: Caso de la organización SSS Susana Sawyer, Álamos, Sonora. Tesis de Maestría en Estudios del Desarrollo Rural, México, Colegio de Postgraduados.

La Agenda 2030 y los Objetivos para el Desarrollo Sostenible. (2015). Agenda 2030 y los Objetivos de Desarrollo Sostenible. Una oportunidad para América Latina y el Caribe. CEPAL. ONU.

Mareswara Rao, N. (2016). A Study on Empowerment of Rural Women Through Entrepreneurial Activities. Social Science. 5(10), 311-313.

Narasimha B.G., et al. (2016). Role of self help groups in women empowerment and health. International Fournal of Community Medicine and Public Health, 3(8), 2026-2028.

Nazar, A. \& Zapata, E. (2000). Desarrollo bienestar y género: consideraciones teóricas. La Ventana, 11, 73-118.

Pérez, N.E. (2001). El proceso de empoderamiento de mujeres indígenas organizadas desde una perspectiva de género. Estudios Agrarios, 17, 125-169. 
Pérez, P.I.; Orozco, G.M. y Cruz, S.Z.M. (2014). Mujeres rurales emprendedoras de la región Istmo-Costa de Chiapas: productoras de totopo y memelita de olla. Researchetnet, 184-201.

Pérez V.M., Vázquez, G.V. y Zapata M.E. (2008). Empoderamiento de las mujeres indígenas de Tabasco. El papel de los fondos regionales de la CDI. Colegio de Postgraduados, Campus Montecillo, Texcoco, Estado de México. Revista Cuicuilco, 15(42).

Rodríguez, B.E. (2009). Género, Cultura y Desarrollo: Límites y oportunidades para el cambio cultural pro-igualdad de género en Mozambique. Instituto Complutense de Estudios Internacionales, Universidad Complutense de Madrid. Madrid, España.

Young, K. (1997). El potencial transformador en las necesidades prácticas: empoderamiento colectivo y el proceso de planificación, en León, M. (Ed.), Poder y empoderamiento de las mujeres, Bogotá, Tercer Mundo, 99-118.

Villarreal, M. (2011). Mujeres rurales y oportunidades: de la participación al empoderamiento. Tend-Red, 16, 243-259. Colombia. 
/03/ 


\section{Análisis de calidad de vida laboral y competitividad en empresas de servicios turísticos}

\section{Quality of work life and competitiveness in tourist service company}

José Octavio Molina Germán

Profesor de tiempo completo, adscrito al Departamento de ciencias económico-administrativas y al programa educativo de Administración de empresas. Universidad de Occidente, Unidad Mazatlán. octavio.udo@hotmail.com

Anel Yadira Pérez Melo

Profesora de Tiempo Completo adscrita al Departamento de Ciencias Económico-Administrativas y al programa educativo de Administración Turística. Miembro del Cuerpo Académico Capital Humano en las Organizaciones. Universidad de Occidente, Unidad Mazatlán. anel.perez@udo.mx

Georgina Lizárraga Salazar

Profesora de Tiempo Completo adscrita al Departamento de Ciencias Sociales y Humanidades y al programa educativo de Psicología. Miembro del Cuerpo Académico Capital Humano en las

Organizaciones. Universidad de Occidente, Unidad Mazatlán. goguil2002@hotmail.com

Ana María Larrañaga Núñez

Profesora de Tiempo Completo adscrita al Departamento de Ciencias Sociales y Humanidades y al programa educativo de Comunicación. Miembro del Cuerpo Académico Capital Humano en las Organizaciones. Universidad de Occidente, Unidad Mazatlán. amlarranaga2607@gmail.com

Recepción: 17/10/2017. Aceptación: 24/01/2018. Publicación: 24/05/2018

Citación sugerida:

Molina Germán, J.O., et al. (2018). Análisis de calidad de vida laboral y competitividad en empresas de servicios turísticos. 3C Empresa: investigación y pensamiento crítico, 7(2), 44-67. DOI: http://dx.doi. org/10.17993/3cemp.2018.070234.44-67/ 


\section{RESUMEN}

El estudio tiene como propósito analizar la relación e influencia de la calidad de vida laboral en el constructo de la competitividad en las empresas de servicios turísticos, particularmente en la hotelería. Para ello, se utilizó una metodología cuantitativa aplicando un cuestionario para contrastar la percepción de las dos variables dirigido a personal directivo y operativo de una empresa de hospedaje de la ciudad de Mazatlán, Sinaloa, México, mismos que fueron seleccionados de forma aleatoria. Los resultados obtenidos muestran similitudes en la percepción del personal sobre la calidad de vida laboral y la competitividad. No obstante, los datos reflejan una relación entre ambas variables casi nula en la percepción de los directivos y medianamente significativa desde la perspectiva de los operativos.

\section{ABSTRACT}

The purpose of the study is analyze the relationship and influence of the quality of working life on the competitiveness in tourism services companies, particularly in the hotel industry. A quantitative methodology was used applying a questionnaire to contrast the perception of the two variables directed to management and operating personnel of a hotel in the city of Mazatlan, Sinaloa, Mexico, which were selected randomly. The results show similarities in the staffs perception of the quality of work life and competitiveness. However, the data show a relationship between the two variables almost null in the manager's perception and medium-significant from employees' perspective.

\section{PALABRAS CLAVE}

Calidad de vida laboral, Competitividad, Empresa de hospedaje, Dimensiones.

\section{KEY WORDS}

Quality working life, Competitiveness, Tourism service companies, Dimensions. 


\section{INTRODUCCIÓN}

Las trasformaciones en el entorno mundial, así como las exigencias de los consumidores e inversionistas, representan tendencias que ejercen una constante presión para que las empresas generen ambientes de trabajo justos y empleados productivos, lo que evidencia la necesidad de reconfigurar los ambientes laborales en aras de garantizar un servicio de alto nivel competitivo.

Zohurul y Siengthai (2009), establecen que uno de los recursos más valiosos para las organizaciones son sus trabajadores, quienes a través de su esfuerzo logran que las empresas perduren y obtengan mejores resultados organizacionales. Así, la productividad y los resultados de la empresa están influenciados por la Calidad de Vida Laboral (CVL) que experimentan sus trabajadores.

Los cambios significativos que han ocurrido en los últimos años han generado condiciones distintas en las perspectivas de los mercados turísticos mundiales, planteando nuevos retos y oportunidades para las empresas de este sector.

La productividad y los resultados de la empresa están influenciados por la Calidad de Vida Laboral (CVL) que experimentan sus trabajadores.

De acuerdo con la Secretaria de Turismo, la actividad turística en México representa el 9\% del Producto Interno Bruto (PIB) y da empleo a más de 7,5 millones de personas (SECTUR, 2014). En el estado de Sinaloa, durante el primer trimestre del 2014, se tuvo un porcentaje de ocupación del 48.2\% a nivel estatal y un 51.3\% en la ciudad de Mazatlán (SECTUR, 2014).

Esta dinámica transforma el quehacer de la gestión directiva y establece la necesidad de analizar y determinar cuáles son aquellos factores, programas y estrategias que harían posible transitar hacia la competitividad.

Al ser este último elemento de naturaleza multifactorial, se considera que un factor de alta significancia se refiere a la calidad de vida en el trabajo, por lo que su estudio se hace necesario e indispensable a fin de entender su complejidad. 


\section{ESTUDIOS PREVIOS}

El análisis de la calidad de vida laboral es de importancia creciente dadas las nuevas formas de organización empresarial y del trabajo que generan en los individuos altos niveles de presión y de estrés laboral, lo que impacta en el rendimiento y en consecuencia en los resultados productivos.

Se concibe, a partir de estas consideraciones, que el análisis de la calidad de vida laboral constituye un elemento básico y diferenciador que puede potenciarse como una muy valiosa ventaja competitiva. Podemos destacar algunos estudios realizados que revelan que la calidad de vida laboral influye sobre el resultado organizacional.

Lau y May, (1998) y Harter, Schmidt y Hayes, (2002), establecen que la Calidad de Vida Laboral (CVL) ofrecida por una organización y percibida como satisfactoria por los empleados, repercute positivamente en la salud física, psíquica y emocional del trabajador, impactando favorablemente en los desempeños y resultados organizacionales.

\section{El análisis de la calidad de vida laboral constituye un elemento básico y diferenciador que puede potenciarse como una muy valiosa ventaja competitiva.}

Asimismo, los estudios realizados por Efraty y Sirgy (1990), demuestran que las organizaciones que generan bienes y/o servicios de calidad a través de adecuadas condiciones de trabajo, así como oportunidades de desarrollo personal/profesional para sus empleados, también son las que obtienen mayores ganancias y mejor consideración social.

Por otra parte, Zohurul y Siengthai (2009), realizan un estudio exploratorio de la influencia de la CVL sobre la satisfacción laboral y el resultado organizacional. Sus descubrimientos indican que la CVL sugiere que la calidad de vida laboral está positivamente relacionada al resultado organizacional pero no fue significativa, sin embargo, encuentran una relación positiva y significativa entre la calidad de vida laboral y la satisfacción laboral de los empleados.

Asimismo, Sauter, Lim y Murphy (1996) reconocen que el resultado organizacional y el bienestar de los trabajadores se refuerzan mutuamente e introducen un modelo desarrollado por el Instituto Nacional de Seguridad Ocupacional y Salud (NIOSH) en su investigación de organizaciones de trabajo saludable. 
Para Sánchez (2013), la GVL se debe adaptar a las particularidades de la organización, considerando el propósito de competitividad de las organizaciones. Asimismo, es necesario compaginar la CVL desde de la organización y desde del trabajador, pues la organización no funciona sin talentos que la operen e impulsen su CVL, crecimiento y competitividad.

En lo que respecta a Argüelles, Quijano y Fajardo (2017) realizaron una investigación en empresas turísticas de Campeche sobre la relación e influencia de la CVL con los resultados de las organizaciones, encontraron que al establecer estrategias enfocadas a mejorar la CVL de los trabajadores esto se refleja en el rendimiento y beneficio de la organización a corto, mediano o largo plazo. 


\section{CALIDAD DE VIDA LABORAL}

El término Calidad de Vida Laboral (CVL), es de gran relevancia en el estudio del capital humano y ha sido abordado desde diferentes perspectivas como se visualiza en las investigaciones realizadas por múltiples autores como Kraut, Dumais y Koch, 1989; Pruijt, 2000; Joshi, Leichne, Melanson, Pruna, Sager, Jo Store, Williams, 2002; Shoaf, Genaidy, Karwowski y Huang, 2004; Cole, Robson, Lemieux-Charles, McGuire, Sicotte y Champagne, 2005; Hart, Ribbing, Abrahamsson, 2005; Che, Beh, Uli y Idris, 2006; Ukko, Tenhunen, y Rantanen, 2008; Zohurul y Siengthai, 2009, (citado por Contreras; Huerta; Pedraja \& Almodóvar Martínez, 2011).

Este concepto presenta cierta dificultad para definirse debido a las características de subjetividad y multidimensionalidad que posee. Es decir, depende de los valores y creencias de los individuos, de aspectos culturales, de historias de vida así como de la valoración que se dé a las necesidades humanas. Por ejemplo, para González (2009), la calidad de vida da cuenta del problema de satisfacción de necesidades, según French (1996), la calidad de vida en el trabajo (CVT) es una filosofía de gestión que mejora la dignidad del empleado, realiza cambios culturales y brinda oportunidades de desarrollo y progreso personal. Por su parte, Gibson (1996) agrega que es una filosofia, un conjunto de creencias que engloban los esfuerzos por incrementar la productividad y mejorar la motivación de las personas, enfatizando la participación de la gente, su dignificación y la eliminación de aspectos disfuncionales de la jerarquía organizacional.

Es necesario señalar que distintos autores hacen la observación de la dificultad que tiene este concepto para operacionalizarse, por lo que cada uno propone diversas variables de abordaje. Para Poza y Prior (1988, citado en Gamero, 2003, p.35) la CVL es la forma en que se produce la experiencia laboral en condiciones objetivas como seguridad e higiene laboral, trabajo, salud laboral, entre otros, así como las condiciones subjetivas del trabajador de cómo lo percibe o vive. Según Toro (2001), la Calidad de Vida Laboral se refiere a aspectos objetivos como son las condiciones y realidades del trabajo que buscan el bienestar y desarrollo de los empleados, considerando aspectos como la retribución, condiciones de salubridad, seguridad e higiene, ambiente social, liderazgo, trato equitativo, entre otros, incluyendo la percepción y la evaluación subjetiva que hace el individuo a las situaciones antes señaladas.

Por otro lado, Havlovic (1991) y Scobel (1975) señalan que algunos de los elementos clave de la CVL son seguridad en el trabajo, satisfacción laboral, sistemas de recompensas, involucramiento de los empleados y resultados organizacionales, (citado en Contreras et al, 2013). Ukko Tenhunen, y Rantanen (2008: 87) afirman que incluye ocho elementos: motivación en el trabajo, oportunidades 
de aprendizaje, satisfacción en el trabajo, atmósfera de trabajo, salud y seguridad, participación en la toma de decisiones, realización de objetivos a nivel personal y de equipo, y sistema de recompensa.

Una clasificación de GVL muy aplicada por investigadores es la que incorpora por un lado la perspectiva del entorno de trabajo, con indicadores centrados en los intereses organizacionales (condiciones y medio ambiente de trabajo, cultura y clima laboral, productividad y efectividad, condiciones de vida, entre otros), y por otro lado una perspectiva psicológica centrada en el individuo (actitudes y valores hacia el trabajo, motivación y satisfacción laboral), Chiang y Krausee, (2008).

Para el objeto de estudio, se seleccionaron las siguientes dimensiones por considerarlas de gran importancia para la medición y observación de la variable de calidad de vida laboral y su relación con la competitividad de la organización.

a) Desarrollo Profesional. Es el proceso por el que las personas progresan a través de una serie de etapas caracterizadas por distintas tareas de desarrollo, actividades y relaciones (Fernández, 2002, p.67).

b) Beneficios socioeconómicos. Incluye las políticas de remuneración, compensación e incentivos, de los trabajadores.

c) Satisfacción en el Trabajo. Abarca diferentes aspectos como el trabajo en sí, salarios e incentivos, supervisión, promociones, ambiente de trabajo, entre otros.

d) Sentido de Pertenencia. La capacidad del individuo de sentirse integrante de un grupo u organización. En la relación empresa-empleado, la pertenencia permite alcanzar objetivos individuales y organizacionales.

e) Participación del Personal. Contempla las capacidades que posee el personal y la apertura de la empresa para el uso de las mismas, así como su participación en la toma de decisiones.

f) Medio ambiente de Trabajo. Factores ambientales que pueden ocasionar enfermedades o efectos negativos en el bienestar del personal. Incluye asimismo la prevención de los accidentes y enfermedades.

Como se observa, la CVL es un proceso que permite a las organizaciones responder a las necesidades de sus empleados para mejorar su vida laboral, su desarrollo profesional y personal. Por lo tanto, se puede decir que la CVL, busca el desarrollo del trabajador, como medio para elevar la eficiencia empresarial. 


\section{COMPETITIVIDAD}

A partir de las exigencias del entorno económico actual y al proceso de globalización en las que se encuentran inmersas las organizaciones, un aspecto que adquiere mayor relevancia es la competitividad. Esto se debe principalmente porque las empresas están obligadas a mantener e incrementar su participación en el mercado, a innovar sus productos y servicios, a flexibilizar sus sistemas de producción, a tener una rápida respuesta a las demandas del entorno, todo ello con una reducción en sus costos y un aumento en su productividad.

No obstante, se considera que la competitividad es un concepto complejo, el cual puede ser estudiado desde diferentes enfoques y disciplinas, incluso algunos autores señalan que no es posible establecer una definición única, en parte debido a que su utilidad reside en identificar vías para fomentar empresas que contribuyan a elevar los niveles reales de bienestar (Solleiro y Castañón, 2005).

Se destacan dos grandes enfoques para abordar la competitividad, uno de ellos es el propuesto por World Competitiveness Center (WCG) del Institute for Management and Development, el cual indica que es el ambiente competitivo de las naciones el que crea y mantiene la competitividad de las empresas. El otro es del Institute for Strategy and Competitiveness (ISC) de la Universidad de Harvard, éste señala que las condiciones macroeconómicas dan las oportunidades pero son las empresas las que crean bienes y servicios con valor agregado usando métodos eficientes.

Bajo estas perspectivas, la competitividad está relacionada con la capacidad de incrementar el nivel de vida de los habitantes, de generar incrementos sostenidos en productividad, de insertarse exitosamente en los mercados internacionales, entre otros (Padilla, 2006, citado por Saavedra, 2012).

Sin embargo, autores como Porter (1990) han señalado que las que compiten son las empresas no las naciones, a un país lo hacen competitivo las empresas competitivas que hay en este. Por lo tanto, son estas la base de la competitividad.

La competitividad empresarial es la capacidad para, rivalizando con otras empresas, alcanzar una posición competitiva favorable, que permita obtener un desempeño superior al de los competidores (Rubio, 2004, Citado en Rubio y Aragón, 2006, p. 105). Solleiro y Castañón (2005), señalan que es la capacidad de una organización para mantener su participación en el mercado basada en nuevas estrategias empresariales, en el crecimiento sostenido de la productividad y en la capacidad para participar en negociaciones con diferentes instituciones. 
La Teoría de los Recursos y las Capacidades sontiene que la rentabilidad de una empresa se encuentra estrechamente vinculada con el tipo, cantidad y naturaleza de sus recursos y capacidades.

La escuela de los recursos internos (Wernerfelt, 1991; Amit y Schoemaker, 1993; Hoopes, Madsen \& Walker, 2003), sostiene que las empresas disponen de recursos y capacidades únicos, que les proporcionan la base para la estrategia.

Bajo este enfoque surge la teoría de los recursos y las capacidades (TRC). Esta sostiene que la rentabilidad de una empresa se encuentra estrechamente vinculada con el tipo, cantidad y naturaleza de sus recursos y capacidades. Amit y Schoemaker (1993), se refieren a estos componentes, como activos estratégicos, los cuales deben ser protegidos y desarrollados para lograr una ventaja competitiva. En esta idea, Prahalad y Hamel (1990) establecen que es un requisito fundamental para los altos ejecutivos poseer la capacidad de identificar, cultivar y aprovechar los recursos y capacidades de la empresa, que representen rentabilidad y crecimiento.

Bajo esta perspectiva se abordan como dimensiones de competitividad:

a) Recursos Tangibles. Elementos productivos físicos o medios financieros.

b) Recursos intangibles. Se clasifican en recursos humanos (formación, experiencia, adaptación), recursos tecnológicos (patentes, conocimiento, experiencia productiva) y reputación de la empresa frente a sus clientes y proveedores.

c) Capacidades. Habilidades y conocimientos que posee la organización para alcanzar objetivos deseados.

d) Competitividad empresarial. Dimensión de contraste para determinar la percepción del desarrollo de nuevos productos, satisfacción del cliente, interés por la formación y desarrollo del personal y por la imagen de la empresa. 


\section{METODOLOGÍA}

El estudio es descriptivo, transversal, correlacional, de corte cuantitativo donde se analiza las variables GVL y competitividad desde la percepción del personal directivo y operativo de una empresa de hospedaje de la ciudad de Mazatlán, Sinaloa.

La empresa fue seleccionada por su representatividad en la localidad, así como por las certificaciones que ostenta como empresa verde (certificación de Profepa), empresa incluyente, y Certificación Great Place To Work. En el momento de la aplicación se contaba con una población de 205 trabajadores, la muestra fue aleatoria integrada por 66 trabajadores que permitiría tener un margen de error de $10 \%$, sin embargo, se descartaron 8 instrumentos, quedando una muestra de 58 sujetos los cuales 10 tiene puesto directivos y el resto operativo. Algunos de los criterios que se consideraron fueron: a) incluir a trabajadores de las 3 jornadas laborales, b) que la muestra contemplara por lo menos $15 \%$ de directivos, c) contar con personal de todos los departamentos que conforman el hotel.

Para medir la GVL, se adaptó el cuestionario diseñado por Huerta, Soler y otros (2003) a partir de juicio de expertos (5) y prueba piloto, resultando un instrumento constituido por 53 ítems, relacionados con seis dimensiones e indicadores (ver tabla 1). 
Tabla 1. Dimensiones CVL.

\begin{tabular}{|c|c|}
\hline DIMENSIONES & INDICADORES \\
\hline Desarrollo profesional & $\begin{array}{l}\text { - Promoción } \\
\text { - Adiestramiento } \\
\text { - Planes de carrera }\end{array}$ \\
\hline Beneficios socioeconómicos & $\begin{array}{l}\text { - Salarios } \\
\text { - Bonos navideños } \\
\text { - Vacaciones } \\
\text { - Atención médica }\end{array}$ \\
\hline Satisfacción en el trabajo & $\begin{array}{l}\text { - Evaluación del desempeño Incentivo, Motivación, Clima } \\
\text { organizacional, Reconocimientos }\end{array}$ \\
\hline Sentido de pertenencia & $\begin{array}{l}\text { - Identidad con la tarea } \\
\text { - Identidad con la empresa } \\
\text { - Imagen corporativa }\end{array}$ \\
\hline Proceso de participación & $\begin{array}{l}\text { - Creatividad y expresión personal } \\
\text { - Repercusiones de ideas aportadas } \\
\text { - Programas de participación en la toma de decisiones }\end{array}$ \\
\hline Medio ambiente de trabajo & $\begin{array}{l}\text { - Higiene industrial } \\
\text { - Orden } \\
\text { - Seguridad } \\
\text { - lluminación } \\
\text { - Temperatura } \\
\text { - Ruidos } \\
\text { - Períodos de descanso }\end{array}$ \\
\hline
\end{tabular}

Fuente: elaboración propia (2017).

Para la variable competitividad, se utiliza el modelo planteado por Fonseca (2007), basado en la TRC. La dimensión recursos tangibles solo aplica al personal directivo. La versión para directivos cuenta con 50 ítems y para personal operativo 30 (ver tabla 2). 
Tabla 2. Dimensiones Competitividad.

\begin{tabular}{|c|c|}
\hline DIMENSIÓN & INDICADOR \\
\hline Recursos tangibles & $\begin{array}{l}\text { - Activo físico } \\
\text { - Activo financiero }\end{array}$ \\
\hline Recursos intangibles & $\begin{array}{l}\text { - Capital humano } \\
\text { - Recursos tecnológicos } \\
\text { - Reputación }\end{array}$ \\
\hline Capacidades & $\begin{array}{l}\text { Capacidad de marketing } \\
\text { Capacidad de distribución } \\
\text { Sistemas de información } \\
\text { Capacidad directiva }\end{array}$ \\
\hline Competitividad empresarial & $\begin{array}{l}\text { - Recursos } \\
\text { - Capacidades }\end{array}$ \\
\hline
\end{tabular}

Fuente: elaboración propia (2017).

El instrumento fue elaborado con escala tipo Likert de cinco alternativas de respuesta con rango $1=$ Muy en Desacuerdo a 5=Muy de Acuerdo.

Los resultados obtenidos se procesaron mediante el programa estadístico SPSS en su versión 22.0, realizando el análisis de confiabilidad, los resultados descriptivos, así como correlacionar las dimensiones de calidad de vida laboral con las variables de competitividad, los cuales se observan en el siguiente apartado. 


\section{RESULTADOS}

Los resultados de confiabilidad del alfa de cronbach arrojó 0,962 y 0,887 para CVL (directivos y operativos) y para competitividad 0,951 y 0,857 (directivos y operativos), por lo que el instrumento es confiable, tomando como referencia el criterio sugerido por George y Mallery (2003), quienes establecen las recomendaciones siguientes para evaluar los coeficientes: $>0.9$ excelente, $>0.8$ bueno y $>0.7$ aceptable.

En los datos sociodemográficos, respecto a directivos, el 40\% tiene antigüedad entre 6-10 años y el 30\% más de 10 años. Respecto a la edad, 40\% está en un rango de 31 a 35 años, un 40\% se divide de forma equitativa entre los 36 a 40 y los 41 a 45 años. El 90\% son hombres. El 90\% posee estudios de licenciatura y 10\% estudios de bachillerato; 60\% cuenta con más de 10 trabajadores a su cargo.

Respecto al personal operativo, el 37.5\% estudió hasta bachiller, 29.2\% secundaria, 14.6\% con licenciatura y $12.5 \%$ estudios comerciales. El 33.3\% tiene una antigüedad entre 3-5 años, 27.1\% menos de 3 años, 20.8\% más de 10 años y 18.8\% tiene entre 6-10 años. El 39.6\% son mujeres y $56.3 \%$ son hombres. Del total 29.2\% tiene una edad entre 18-25 años, 25\% se ubican entre 26-30 años, seguidos por el 20.8\% de 31-35 años igual que los de $41-45$ años, el 75\% está por debajo de los 36 años.

Tabla 3. Baremos y medias de Calidad de vida laboral global y sus dimensiones.

\begin{tabular}{|c|c|c|c|c|c|c|c|c|}
\hline & CVL GLOBAL & $\begin{array}{c}\text { DESARROLLO } \\
\text { PROFESIONAL }\end{array}$ & $\begin{array}{c}\text { BENEFICIOS } \\
\text { SOCIOECONÓMICOS }\end{array}$ & $\begin{array}{c}\text { SATISFACCIÓN } \\
\text { EN EL TRABAJO }\end{array}$ & $\begin{array}{c}\text { SENTIDO DE } \\
\text { PERTENENCIA }\end{array}$ & $\begin{array}{c}\text { PROCESO DE } \\
\text { PARTICIPACIÓN }\end{array}$ & $\begin{array}{c}\text { MEDIO AMBIENTE } \\
\text { DE TRABAJO }\end{array}$ \\
\hline & RANGOS & RANGOS & RANGOS & RANGOS & RANGOS & RANGOS & RANGOS \\
\hline CRITERIOS & DIR OPER & DIR OPER & DIR OPER & DIR OPER & DIR OPER & DIR & OPER & DIR OPER \\
\hline BAJO & $0-123$ & $0-16$ & $0-16$ & $0-22$ & $0-16$ & $0-23$ & $0-28$ \\
\hline MEDIO & $124-194$ & $17-25$ & $17-25$ & $23-36$ & $17-25$ & $24-36$ & $29-44$ \\
\hline ALTO & $195-265$ & $26-35$ & $26-35$ & $37-50$ & $26-35$ & $37-50$ & $45-60$ \\
\hline MEDIA & $\mathbf{2 3 8 - 2 1 7}$ & $\mathbf{3 2}-\mathbf{3 0}$ & $\mathbf{3 2}-\mathbf{2 9}$ & $\mathbf{4 5}-\mathbf{4 2}$ & $\mathbf{3 2}-\mathbf{3 0}$ & $\mathbf{4 4}-\mathbf{3 6}$ & $\mathbf{5 3}-\mathbf{5 0}$ \\
\hline
\end{tabular}

Fuente: elaboración propia (2017). 


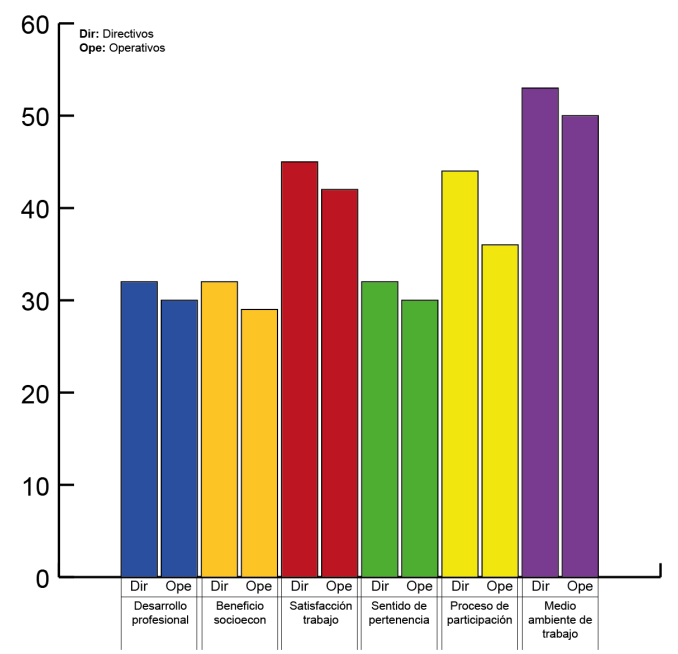

Gráfica 1. Medias de las dimensiones de Calidad de vida laboral. Fuente: elaboración propia (2017).

Los resultados para la dimensión global de calidad de vida laboral en la tabla 3, muestran una media de 237.75 para los directivos y 216.90 para el personal operativo, lo que ubica a esta variable en un resultado alto de acuerdo con los criterios establecidos en los baremos.

Los resultados de las dimensiones desarrollo profesional, beneficios socioeconómicos, satisfacción en el trabajo, sentido de pertenencia, procesos de participación y medio ambiente de trabajo, (tabla 3 y gráfica 1), muestran una tendencia favorable, ya que las medias que se obtienen para directivos y operativos reflejan una puntuación alta. 
Tabla 4. Baremos y medias de Competitividad y sus dimensiones.

\begin{tabular}{|c|c|c|c|c|c|c|c|c|c|}
\hline \multirow[b]{3}{*}{ CRITERIOS } & \multirow{2}{*}{\multicolumn{2}{|c|}{$\begin{array}{c}\text { COMPETITIVIDAD } \\
\text { GLOBAL } \\
\text { RANGOS }\end{array}$}} & \multirow{3}{*}{$\begin{array}{l}\text { RECURSOS } \\
\text { TANGIBLES* } \\
\text { RANGOS } \\
\text { DIR }\end{array}$} & \multirow{2}{*}{\multicolumn{2}{|c|}{$\begin{array}{l}\text { RECURSOS } \\
\text { INTANGIBLES } \\
\text { RANGOS }\end{array}$}} & \multirow{2}{*}{\multicolumn{2}{|c|}{$\begin{array}{l}\text { CAPACIDADES } \\
\text { RANGOS }\end{array}$}} & \multirow{2}{*}{\multicolumn{2}{|c|}{$\begin{array}{c}\text { COMPETITIVIDAD } \\
\text { EMPRESARIAL } \\
\text { RANGOS }\end{array}$}} \\
\hline & & & & & & & & & \\
\hline & DIR & OPER & & DIR & OPER & DIR & OPER & DIR & OPER \\
\hline BAJO & $0-177$ & $0-70$ & $0-21$ & $0-42$ & $0-35$ & $0-33$ & $0-16$ & $0-21$ & $0-14$ \\
\hline MEDIO & $118-185$ & $71-110$ & $22-33$ & $43-66$ & $36-55$ & $34-52$ & $17-25$ & $22-33$ & $15-22$ \\
\hline ALTO & $186-250$ & $111-150$ & $34-45$ & $67-90$ & $56-75$ & $53-70$ & $26-35$ & $34-45$ & $23-30$ \\
\hline MEDIA & 217 & 127 & 38 & 78 & 67 & 60 & 29 & 40 & 25 \\
\hline
\end{tabular}

Fuente: elaboración propia (2017).

* Solo aplica para directivos.

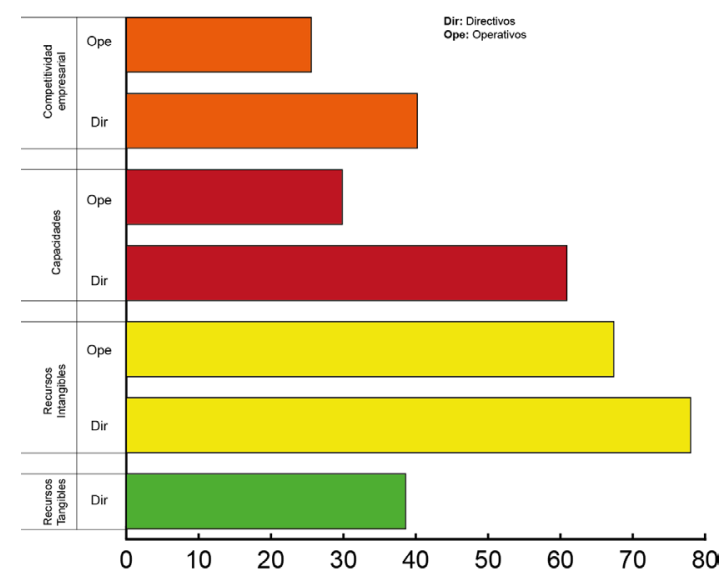

Gráfica 2. Medias de las dimensiones de Competitividad.

Fuente: elaboración propia (2017) 
Tabla 5. Correlación entre las variables Calidad de vida laboral y competitividad en Directivos.

\begin{tabular}{|c|c|c|c|c|c|}
\hline 1. Recursos tangibles & & \multirow{4}{*}{1} & \multirow{4}{*}{2} & \multirow{4}{*}{3} & \multirow{4}{*}{4} \\
\hline 2. Recursos intangibles & & & & & \\
\hline 3. Capacidades & & & & & \\
\hline 4. Competitividad empresarial & & & & & \\
\hline \multirow{2}{*}{ Desarrollo Profesional } & \multirow{2}{*}{ Correlación de Pearson Sig. } & .261 & .479 & .522 & .367 \\
\hline & & .467 & .161 & .150 & .332 \\
\hline \multirow{2}{*}{ Beneficios Socioeconómicos } & \multirow{2}{*}{ Correlación de Pearson Sig. } & -.058 & .188 & .294 & .480 \\
\hline & & .873 & .602 & .443 & .191 \\
\hline \multirow{2}{*}{ Satisfacción en el trabajo } & \multirow{2}{*}{ Correlación de Pearson Sig. } & .178 & .168 & -.006 & .496 \\
\hline & & .647 & .665 & .989 & .211 \\
\hline \multirow{2}{*}{ Sentido de pertenencia } & \multirow{2}{*}{ Correlación de Pearson Sig. } & .260 & .343 & .255 & .584 \\
\hline & & .468 & .332 & .508 & .098 \\
\hline \multirow{2}{*}{ Proceso de participación } & \multirow{2}{*}{ Correlación de Pearson Sig. } & .289 & .649 & .427 & $.830^{*}$ \\
\hline & & .450 & .059 & .292 & .011 \\
\hline \multirow{2}{*}{ Medio ambiente de trabajo } & \multirow{2}{*}{ Correlación de Pearson Sig. } & .341 & .367 & .328 & .430 \\
\hline & & .336 & .296 & .390 & .248 \\
\hline
\end{tabular}

La tabla anterior evidencia desde la perspectiva de análisis de la información que se obtuvo de los directivos, que no existe correlación entre las dimensiones de las variables calidad de vida laboral y competitividad, exceptuando la dimensión proceso de participación con competitividad empresarial que manifiesta una correlación 0,830 y una significancia para el nivel de confianza de 0,011.

Tabla 6. Correlación entre las variables Calidad de vida laboral y competitividad del personal operativo.

\begin{tabular}{|c|c|c|c|c|}
\hline 1. Recursos tangibles & & \multirow{4}{*}{1} & \multirow{4}{*}{2} & \multirow{4}{*}{3} \\
\hline 2. Recursos intangibles & & & & \\
\hline 3. Capacidades & & & & \\
\hline 4. Competitividad empresarial & & & & \\
\hline \multirow{2}{*}{ Desarrollo Profesional } & \multirow{2}{*}{ Correlación de Pearson Sig. } & .222 & .106 & .230 \\
\hline & & .142 & .485 & .124 \\
\hline \multirow{2}{*}{ Beneficios Socioeconómicos } & \multirow{2}{*}{ Correlación de Pearson Sig. } & -.239 & .179 & $.294^{*}$ \\
\hline & & .105 & .224 & .042 \\
\hline \multirow{2}{*}{ Satisfacción en el trabajo } & \multirow{2}{*}{ Correlación de Pearson Sig. } & $.297^{*}$ & $.302^{*}$ & $.509^{\star *}$ \\
\hline & & .042 & .037 & .000 \\
\hline \multirow{2}{*}{ Sentido de pertenencia } & \multirow{2}{*}{ Correlación de Pearson Sig. } & $.446^{* *}$ & $.352^{*}$ & $.406^{\star *}$ \\
\hline & & .002 & .015 & .005 \\
\hline \multirow{2}{*}{ Proceso de participación } & \multirow{2}{*}{ Correlación de Pearson Sig. } & .248 & .177 & .130 \\
\hline & & .101 & .239 & .388 \\
\hline \multirow{2}{*}{ Medio ambiente de trabajo } & \multirow{2}{*}{ Correlación de Pearson Sig. } & $.482^{* *}$ & $.302^{*}$ & .211 \\
\hline & & .001 & .039 & .155 \\
\hline
\end{tabular}


Desde la perspectiva del personal operativo, en la tabla 6 se muestra que existen relaciones moderadas entre la dimensión de satisfacción en el trabajo con la competitividad empresarial con un resultado de 0,509. Entre la dimensión de sentido de pertenencia respecto a los recursos intangibles, capacidades y la competitividad empresarial cuyos resultados son 0,446, 0,352 y 0,406 con valores de significancia de 0,002, 0,015 y 0,005. Entre la dimensión medio ambiente de trabajo respecto a los recursos intangibles y las capacidades que muestran una relación de 0,482 y 0,302 con valores de significancia de 0,001 y 0,039 respectivamente.

Se infiere que un porcentaje superior al 90\% del personal de la empresa estudiada considera que su CVL se encuentra a un nivel alto. Esto supone que la organización desarrolla actividades orientadas a la transformación de ideas y actitudes, que la remuneración y las políticas salariales son favorables, que diseña estrategias para la satisfacción personal y al mejoramiento de las condiciones de trabajo. Asimismo, que promueve una participación de su personal identificado con la tarea, empresa e imagen corporativa, incidiendo en el rendimiento y la competitividad de la organización. 


\section{DISCUSIÓN}

Con los resultados obtenidos, se puede inferir que un porcentaje superior al $90 \%$ del personal que labora en la empresa objeto de estudio, considera que su calidad de vida laboral se encuentra a un nivel alto. Esto indica que la empresa ofrece condiciones relacionadas con las dimensiones de calidad de vida laboral que genera una percepción de satisfacción y que ello se traduce en resultados favorables que impactan el rendimiento y la competitividad de la organización.

Los resultados en cuanto a la GVL, difieren con los obtenidos por Huerta, Soler y otros (2003), que presentan resultados ubicados en un nivel medio. Los datos que arroja esta investigación son mayormente puntuaciones favorables percibiendo a esta variable en el rango más alto de acuerdo con los criterios establecidos.

En lo que respecta a competitividad, se observa una percepción favorable por parte de directivos y personal operativo, ellos consideran que la organización logra sus objetivos y metas a través del uso adecuado de los recursos y desarrollo de estrategias eficaces.

Zohurul y Siengthai (2009), descubrieron que la GVL está relacionada al resultado organizacional pero no significativamente, excepto en la dimensión satisfacción laboral de los empleados, respecto a ello, encontramos similitudes principalmente en los datos de directivos. El estudio refleja una relación positiva y significativa entre la dimensión proceso de participación y la dimensión competitividad empresarial. En tanto los datos correspondientes al personal operativo evidencia relaciones moderadas en las dimensiones de satisfacción en el trabajo, sentido de pertenencia y medio ambiente de trabajo, respecto a la competitividad empresarial y los recursos intangibles. 


\section{CONCLUSIONES}

El estudio se realizó con el propósito de analizar la calidad de vida laboral y la competitividad percibida por los empleados de una organización turística con sede en la ciudad de Mazatlán, Sinaloa, México. Una vez procesada y analizada la información recabada mediante el trabajo de campo se puede establecer en términos generales que el nivel de calidad de vida laboral de los empleados en la empresa estudiada es alto, lo que indica que las personas perciben que la organización logra satisfacer de manera significativa las necesidades relacionadas con el desarrollo profesional, beneficios socioeconómicos, satisfacción en el trabajo, sentido de pertenencia y medio ambiente de trabajo.

Sólo la dimensión de proceso de participación para el personal operativo se ubicó en el límite superior del rango medio de la puntuación, entendiéndose este resultado como parte de un fenómeno generalizado que caracteriza a las organizaciones ya que en la mayoría de ellas los procesos de participación y la toma de decisiones representan acciones que regularmente se reservan para los cuadros o equipos de dirección.

\section{Las personas perciben que la organización logra satisfacer de manera significativa las necesidades relacionadas con el desarrollo profesional, beneficios socioeconómicos, satisfacción en el trabajo, sentido de pertenencia y medio ambiente de trabajo.}

En cuanto a los resultados de la variable competitividad, se observa una percepción favorable con rango más alto en las dimensiones de recursos tangibles, intangibles, capacidades y competitividad empresarial. Esto indica que la empresa emplea los recursos disponibles adecuadamente, desarrollando estrategias directivas eficaces orientadas a las actividades financieras, procesos de producción e innovación, investigación de mercados, mejoramiento de la calidad e imagen de la empresa, procesos de comunicación y participación, así como al desarrollo de las capacidades de los empleados.

Para futuros estudios es importante considerar el carácter multidimensional de la variable CVL y analizarla en contraste con otras variables para la comprensión multifactorial de esta variable. Asimismo, desarrollar estudios que permitan enfatizar en la correlación entre ambas dimensiones para definir a que factores puede ser posible atribuir una mayor influencia y con ello diseñar 
estrategias de mejoramiento de la competitividad de las empresas, asimismo, ampliar el estudio a otras empresas del sector para evaluar si existen diferencias significativas en los resultados. 


\section{REFERENCIAS BIBLIOGRÁFICAS}

Amit, R. y Schoemaker, P. (1993). Strategic assets and organizational rent. Strategic Management Journal, 14, 33-46.

Argüelles, M.A., Quijano, L.A. y Fajardo, M.A. (2017). Rentabilidad y Calidad de Vida Laboral, Revista Internacional Administración \& Finanzas, 10(1), pp. 81-93.

Chiang M., y Krausse A. (2008). Estudio empírico de calidad de vida laboral, cuatro indicadores: satisfacción laboral, condiciones y medioambiente del trabajo, organización e indicador global, sectores privado y público. Desarrollo, aplicación y validación del instrumento. Horizontes empresariales, 3, 23-50.

GODESIN. (2015). Reporte de llegada de turistas y ocupación hotelera en Sinaloa, de enero a diciembre de 2015. Disponible en: http://sinaloaennumeros.com/reporte-de-llegada-deturistas-y-ocupacion-hotelera-en-sinaloa-de-enero-a-diciembre-de-2015/

Efraty, D. y Sirgy, M. (1990). The effects of Quality of Working life (QWL) on employee behavioral responses. Social Indicators Research, 22, 31- 47.

Fernández Losa, N. (2002). El desarrollo profesional de los trabajadores como ventaja competitiva de las empresas. Cuadernos de Gestión, 2(1), 65-90.

Fonseca Lupiac, K.J. (2007). Los recursos tangibles, intangibles y las capacidades como factores explicativos de la competitividad empresarial de las mipymes del sector industrial en Nicaragua. (Tesis inédita de doctorado). Universidad Católica de Honduras.

French, W. (1996). Desarrollo Organizacional, Editorial Prentice Hal.

Gamero, G. (2003). Análisis económico de la satisfacción laboral. (Tesis inédita de doctorado). Facultad de ciencias económicas y empresariales, departamento de economía aplicada (estadística y econometría). Universidad de Málaga.

García Meier, E. (2014). Percepción de Calidad de Vida Laboral del personal operativo y administrativo en empresas de consumo masivo. (Tesis inédita de licenciatura). Universidad Rafael Urdaneta.

Gibson, I.D. (1996). Las Organizaciones, Editorial McGraw Hill, Madrid. 
González, L. J. (2009). Tendencias en la calidad de vida en países con dependencia mineral. Revista de Ciencias Sociales, 15(2). Maracaibo, Venezuela, 272-283.

Harter, J.K., Schmidt, F.L., y Hayes, T.L. (2002). Business unit-level relationship between employee satisfaction, employee engagement, and business outcomes: A meta-analysis, Fournal of Applied Psychology, 87(2), 268-279.

Hernández, R., Fernandez, G. y Baptista, P. (2003). Metodología de la investigación. Editorial Mac GrawHill. Chile.

Huerta, Soler y Duran (2003). Evaluación de la Calidad de Vida Laboral del personal administrativo de IPPLUZ. Unversidad Rafael Belloso Chacín. Venezuela.

Lau, R. y May, B. (1998). A Win- Win Paradigm for Quality of Worklife and Bussiness Performance. Human Resource Developpment Quarterly, 9(3), 211- 227.

Prahalad, G. y Hamel, G. (1990). The core competence of the corporation. Harvard Business Review, mayo-junio, .79-91.

Rubio Bañón, A. y Aragón Sánchez, A. (2006) Recursos estratégicos en las pymes. Revista Europea de Dirección y Economía de la Empresa, 17(1). 103-126.

Sánchez Ortiz, D.L. (2013). Influencia de la Calidad de Vida Laboral en los Individuos y las Organizaciones. Universidad de La Sabana, Facultad de Psicología. Disponible en: https:// intellectum.unisabana.edu.co/bitstream/handle/10818/9788/Dayana\%20Lorena\%20 S\%C3\%Alnchez $\% 20$ Ortiz $\% 20 \% 28$ TESIS\%29.pdf? sequence=1\&isAllowed $=\mathrm{y}$

Secretaria de Turismo. (2017). Empleo Turístico, Datatur. Disponible en: http://www.datatur. sectur.gob.mx/SitePages/ResultadosITET.aspx

Solleiro, J. y Castañón, R. (2005). Competitividad y sistemas de Innovación: Los retos para la inserción de México en el Contexto Global. Revista Iberoamericana, 5, p.15.

Ukko, J., Tenhunen, J. y Rantanen, H. (2008). The Impacts of Performance Measurement on the Quality of Working Life. Business Performance Management, 10(1), 86-98.

Wernerfelt, B. (1991). A Resource-Based View of The Firm. Strategic Management Journal, 5, 171-180. 
Zohurul, I. y Siengthai, S. (2009). Quality of Work Life and Organizational Performance: Empirical Evidence from Dhaka Export Processing Zone. This paper is prepared for the ILO Conference on 'Regulating for Decent Work, to be held at the International Labour Office, Geneva. 
/04/ 


\section{Bahía de Altata, Navolato - Nuevo modelo de desarrollo turístico sostenible}

\section{Altata Bay, Navolato - New sustainable touristic model of development}

Martín León Santiesteban

Doctor en Gestión del Turismo. Docente de la Maestría de Gestión y Políticas Públicas de la Universidad de Occidente, Culiacán (México). ORCID: http:// orcid.org/0000-0002-8632-3833

martin.leon@udo.mx

Juan Pablo Mariño Jiménez

Doctor en Gestión del Turismo. Profesor Investigador de la Universidad Antonio Nariño, Bogotá

(Colombia).

jupamarino@gmail.com

Recepción: 26/07/2017. Aceptación: 03/03/2018. Publicación: 24/05/2018

Citación sugerida:

León Santisesteban, M. y Mariño Jiménez, J.P. (2018). Bahía de Altata, Navolato - Nuevo modelo de desarrollo turístico sostenible. 3C Empresa: investigación y pensamiento crítico, 7(2), 68-85. DOI: http://dx.doi. org/10.17993/3cemp.2018.070234.68-85/ 


\section{RESUMEN}

El presente capítulo permea el nivel de marginación de la población, la afluencia de visitantes y la fragilidad ecológica de los recursos naturales presentes dentro de la bahía de Altata y Navolato como determinantes para el desarrollo de nuevos proyectos con fines turístico - recreativos en la zona. Se encuentra pertinente evaluar la potencialidad de los recursos y atractivos existentes a la luz de potenciales atractivos turísticos sostenibles que permitan generar una diversificación económica sin elevar el deterioro ambiental que actualmente se está presentando. Finalmente, se dan a conocer los resultados de la aplicación de una metodología de evaluación cualitativa de los recursos de Altata, Navolato, encaminada a desarrollar un producto turístico de bajo impacto enfocado en actividades de turismo alternativo.

\section{ABSTRACT}

In this paper is easy to observe the level of marginalization of the population, the flow of visitors and the ecological fragility of this touristic area. It provides guidelines for developing new projects on the recreational-touristic use of resources with which it counts, which will generate economic diversification without raising the environmental deterioration that is currently taking place. In this way, it is necessary to make a comparison of the potential of existing resources and propose touristic sustainable products. The present document intends to present the results of the application of a methodology of qualitative evaluation of the resources of Altata, Navolato. In order to know its design as a low-impact touristic product focus on alternative touristic activities.

\section{PALABRAS CLAVE}

Altata, Recursos Naturales, Medio Ambiente, Sustentabilidad.

\section{KEY WORDS}

Altata, Natural resources, Environment, Sustainability. 


\section{INTRODUCCIÓN}

El objetivo del presente artículo es el de analizar los modelos de desarrollo para sentar las bases teóricas y metodológicas en la comprensión del fenómeno de masificación hacia la oferta de sol y playa, sus repercusiones en los recursos naturales, culturales y humanos, y su contraparte hacia el desarrollo de un turismo alternativo con prácticas sustentables y de bajo impacto.

\section{Se pretende evidenciar los resultados de la aplicación de una metodología de evaluación cualitativa de los recursos de Altata, Navolato, con el fin de conocer su diseño como un producto turístico.}

No es difícil observar el nivel de marginación de la población, la afluencia de visitantes y la fragilidad ecológica de esta zona turística, los cuales dan pauta para desarrollar nuevos proyectos sobre el uso recreativo-turístico de los recursos con los que cuenta, los cuales permitirán generar una diversificación económica sin elevar el deterioro ambiental por el que actualmente está pasando.

En el presente documento se pretende evidenciar los resultados de la aplicación de una metodología de evaluación cualitativa de los recursos de Altata, Navolato, con el fin de conocer su diseño como un producto turístico de bajo impacto enfocado a actividades de turismo alternativo.

Por lo tanto, se enmarca la definición de la sostenibilidad e incluye a esta Bahía para una mejor comprensión para su estudio futuro. Adicionalmente, se expone la metodología utilizada este documento, asimismo, se desarrolla un análisis sociodemográfico del puerto y se realiza la identificación del inventario turístico como potenciales a desarrollar en este lugar, tomando de referencia las propuestas realizadas por la Secretaria de Turismo (Sectur). Finalmente, se presentan las conclusiones del lugar en estudio la Bahía de Altata. 


\section{SOSTENIBILIDAD}

La sostenibilidad es un concepto cuyo origen se remonta a la década de los años ochenta del siglo pasado, el cual surge a partir de las diversas perspectivas científicas que para entonces discutían en torno a la relación existente entre el medio ambiente y las actividades económicas y productivas propias de la sociedad moderna (Medina, 2008).

Dentro de este contexto, Espino (2015), asegura que la sostenibilidad vincula todas aquellas necesidades económicas y biológicas con el propósito de estimar la magnitud del consumo humano, por lo que es un concepto ecléctico que se nutre de la economía, la sociedad y lo ambiental en procura de un bien común.

Organismos como Conservation of Nature and Natural Resources (IUCN), United Nations Environment Programme (UNEP) y World Wildlife Fund (WWF) (1980) refieren que la «sostenibilidad» surgió como resultado de analizar la situación del mundo en términos de afectación al medio ambiente, cuyo impacto en aquel entonces, constituía una situación insostenible que podía afectar el futuro de la humanidad.

En la Conferencia de las Naciones Unidas sobre el Medio Ambiente y Desarrollo de 1992, conocida como Cumbre de Río de Janeiro y se adopta la perspectiva planteada en la denominada Agenda 21, donde se declara cómo el desarrollo económico debe darse de manera paralela con el desarrollo social, en virtud a que las problemáticas de sobrexplotación del planeta están simbióticamente relacionadas con las realidades económicas y las disfunciones a nivel de justicia social (Guimarães, 2001).

Es por eso que, la explotación racional del medio ambiente, el trato consensuado con las comunidades locales y en general aquellos aspectos referidos por un gran número de autores a la hora de conceptualizar frente a la sostenibilidad, se enfocan mayoritariamente en las actividades industriales. Sin embargo, existen actividades que, como el turismo, tienen igual o mayor compromiso con las tres aristas de la sostenibilidad sin que dentro de su desarrollo medie un proceso fabril.

En este sentido, Ventura (2011), manifiesta que el turismo no es un producto, pero sí un complejo conjunto de servicios turísticos que se complementan con algunos bienes necesarios para la prestación de los mismos, cuya característica principal es la simultaneidad en la producción y el consumo geográficamente localizado en un espacio específico denominado destino turístico.

Es por tal razón que, ante la preeminencia de recursos de índole natural y cultural en los destinos 
turísticos Crouch (2007), enfatiza en que la sostenibilidad es el fundamento para conseguir factores de competitividad. Por lo que, investigadores como Diéguez, Gueimonde, Sinde, y Cerradelo (2011), destacan que la competitividad de los destinos turísticos puede incrementarse mediante una gestión basada en la calidad medioambiental y en el desarrollo de un turismo sostenible.

Para Ritchie y Crouch (2000), señalan que un destino turístico competitivo debe ser viable no únicamente en el plano económico sino también en lo ecológico, social, cultural y político, puesto que más allá de propender por una derrama económica producto de la explotación de los atractivos disponibles, la competitividad turística debe garantizar la sostenibilidad de los destinos.

Por lo tanto, promocionar los destinos bajo un criterio netamente comercial, conduce al abandono del principio de sostenibilidad (Ritchie y Crouch, 2003) y desconoce las implicaciones y los impactos que a nivel ambiental, cultural, económico y social trae consigo la actividad turística (Palma, 2007).

Al respecto, Diéguez, Gueimonde, Sinde, y Cerradelo (2011), (citando a Hassan, 2000), señalan que los destinos que consiguen tasas de crecimiento más elevadas son aquellos que establecen estrategias orientadas a la sostenibilidad medioambiental del turismo. No obstante Gómez (2011), crítica a la manera como la actividad turística ha sido asociada con una fórmula redentora de fácil consecución que pretende el logro de la competitividad a partir de los elementos medioambientales.

En este orden de ideas, según Ritchie y Crouch (2003), las ventajas competitivas o recursos desplegados son el resultado de la explotación sustentable de las ventajas comparativas a través del control, mantenimiento y mejoramiento de los recursos de un destino, dando cuenta de una gestión eficiente y eficaz en el largo plazo. De este modo, las ventajas comparativas de un destino turístico pueden evolucionar a ventajas competitivas dependiendo de la gestión que se desarrolle en procura potencializar su estructura, infraestructura y superestructura. 


\section{METODOLOGÍA}

Como fue señalado al principio, el objetivo del presente estudio es el evidenciar los resultados de la aplicación de una metodología de evaluación cualitativa de los recursos de Altata, Navolato, con el fin de conocer su diseño como un producto turístico de bajo impacto enfocado a actividades de turismo alternativo.

De esta manera, el enfoque cualitativo, para Cortes e Iglesias (2004), es una vía de investigar sin mediciones numéricas, tomando encuestas, entrevistas, descripciones, puntos de vista de los investigadores, reconstrucciones de los hechos, no tomando en general la prueba de hipótesis como algo necesario, y se llaman holísticos porque aprecian las cosas como un todo, sin reducirlos a sus partes.

En este sentido, se utilizó el método etnográfico basada en la observación, considerando recoger la información sobre las relaciones sociales y económicas de la población, para este caso se realiza un informe que incorpora la información recolectada y plasmada en una descripción integral de la comunidad en forma de monografía escrita (Angrosino, 2012). 


\section{SITUACIÓN SOCIO-DEMOGRÁFICA}

La Bahía de Altata se distribuye en 9 mil 100 hectáreas y se encuentra ubicado en el municipio de Navolato a 29 kilómetros de la cabecera municipal y a 60 kilómetros de Culiacán, capital del Estado de Sinaloa. Es posible arribar por la autopista a cuatro carriles Culiacán-Altata a través del uso del transporte urbano o bien en vehículo particular y en donde se pueden disfrutar de sus playas, pudiéndose practicar deportes acuáticos, la pesca, el motociclismo, el ciclismo y paseos en vehículos todo terreno (GES, 1990).

Igualmente, y a 5 kilómetros, del otro lado de la bahía, se encuentran las playas de El Tambor, donde se ha iniciado el desarrollo turístico de Nuevo Altata actualmente llamado Isla Cortes. Algunos de los factores que hacen particular a este sitio son el: el clima seco cálido con lluvias en verano y escasas a lo largo del año, lo registros indican que su temperatura oscila en promedio anual entre $\operatorname{los} 24^{\circ} \mathrm{C}(\mathrm{GES}, 1990)$.

\section{La Bahía de Altata tiene una afluencia constante de visitantes, principalmente los fines de semana, quienes llegan a disfrutar de sus atractivos y principalmente de su gastronomía a base de productos del mar.}

Su litoral se compone de una superficie baja y arenosa, donde sus mareas tienen características peculiares por ser de tipo mixto, es decir, con una combinación diurna de subida y bajada cada 24 horas. Esta Bahía se une a un extremo sur de la Isla de Redo y la punta del noroeste de la Península de la Lucernilla. Una de las principales actividades económicas de la Bahía de Altata es la captura de diversos productos marinos, entre los que destacan los de escama, moluscos y de los productos más importantes por el valor se encuentra el camarón dentro de la variedad de crustáceos.

Por último, la Bahía de Altata tiene una afluencia constante de visitantes, principalmente los fines de semana, quienes llegan a disfrutar de sus atractivos y principalmente de su gastronomía a base de productos del mar. Estas visitas a la playa se hacen por espacios cortos de tiempo de aproximadamente seis horas, ya que no cuenta con infraestructura hotelera. 


\section{OFERTA DE SERVICIOS EN ALTATA VS. ISLA CORTES (NUEVO ALTATA)}

La clasificación que se puede otorgar a este enclave turístico ubicado en la Bahía de Altata, en el municipio de Navolato, es para contextualizarlas, dependiendo de sus características, como zona turística, en este sentido se realiza una descripción considerando la elaboración de un sencillo inventario que integra la información descriptiva más relevante de los recursos de cada región, considerando que es un trabajo de valoración y de estructura de los productos que se ofertan en estos dos centros turísticos.

\subsection{ALTATA}

En este sitio turístico se observaron características preturísticas. De acuerdo con Molina (2007) se trata de ofertas y empresas que tienen bajo componente relativo de tecnologías y sistemas administrativos, el personal no requiere capacitación, no se promocionan, y registran instalaciones rudimentarias, siendo esto apreciado por los visitantes y pobladores, de ello, se da cuenta cuando concluye la carretera a cuatro carriles y pasa a circular en una calle normal de tierra a orilla de la playa.

Los restaurantes dan muestra del tipo de construcción en la diversidad de materiales utilizados, la mayoría cuenta con piso de cemento, sanitarios, cocina separada del área de los comensales, bardas bajas con vista a la playa, techos de palma en algunos casos y otros de cemento, cuenta con sistemas de abanicos, las mesas y sillas se observan en su mayoría estar elaboradas de madera y en pocos casos de plástico.

El personal que atiende al comensal en muchos de los casos corresponde a familiares dueños de los restaurantes y en algunos casos incorpora a niños a quienes se observa el ir y venir del restaurante al local con productos solicitados por los comensales. No se observan señalamientos respecto al estado que guarda las mareas, si bien es cierto que no existen olas en esta parte de la bahía, también es cierto la poca atención que se le presta a este tipo de señalamientos cuando las mareas son altas y se elevado el flujo de sus corrientes.

El cuidado al medio ambiente es claro que no existe un compromiso con la naturaleza en esta zona, pues al recorrer por la parte posterior del pueblo se encuentran grandes depósitos de basura cercanos a un manglar que conecta a un estero de la misma bahía. Se observa tala de árboles y mangles y, como consecuencia acarrea problemas de contaminación ambiental y visual, así mismo 
es un foco de infecciones para la misma población ya que se encuentra a escasos 300 metros de las viviendas.

Finalmente, en este apartado es importante señalar la falta de un muelle que pudiera considerarse exclusivo para las embarcaciones menores propiedad de pescadores, se observan dos, pero no cuenta con las condiciones para considerarse embarcadero, sino que son utilizados para aquellas unidades que realizan paseos a quienes visitan estas playas.

\subsection{ISLA CORTES (NUEVO ALTATA)}

En esta nueva infraestructura que se desarrolla se observan condiciones de un turismo industrial maduro, Molina (2006) explica que, en esta etapa, el turismo se instrumenta como una industria, es decir, un conjunto de empresas con diversos giros, que se guían por su código conceptual y operativo en el que predominan los principios de uniformización, centralización y maximización.

En el trayecto a la Isla Coretes, de oriente a poniente, la llegada a esta zona se realiza desviándose de la carretera de cuatro carriles a la derecha, con rumbo al campo pesquero de Dautillos, en el trayecto, kilómetro 6, se toma la desviación a la izquierda para topar con la entrada que da paso para cruzar el puente que conecta la bahía con la península. De esta manera, los visitantes pueden acceder al sitio cruzando un puente, considerado como emblemático por los lugareños, una vez en la parte más alta del mismo, la vista panorámica a ambos lados, se puede observar la belleza de la bahía a través del gran canal y del espeso manglar que lo adorna.

En el trayecto y al cruzar el puente se observan palmeras, las cuales fueron plantadas intencionalmente. Éstas no forman parte del tipo de vegetación propia de la región, adicionalmente en el trayecto la misma vía pasa a ser de cuatro carriles, es muy visible el espectacular que anuncia la llegada al sitio con su característico color azul y grandes letras blancas, se identifica en la parte baja del mismo, los logos de los sitios sociales, dando muestra de ser un lugar moderno.

Por lo que respecta al área de departamentos, estos se encuentran adornados con palma en sus techos y presumen de tener balcones construidos con maderos típicos de la sierra como es palo de Brasil y tablas de caoba o pino. Así mismo, se observa la construcción de un lago artificial, el cual agrega valor económico a este tipo de vivienda y, en el cual se permite realizar actividades acuáticas como son el cayac o pequeños botes impulsados por remos y no se permite circular con motor fuera de borda.

Se observa entre la vegetación unos techos de palma, los cuales se confunden con las ramas de 
mangle negro, acercándose se ubica un gran estacionamiento para los vehículos y da paso a la entrada al Club de Playa "Puesta del Sol", al ir ingresando pasa por un puente elevado de maderas bien talladas de forma circular, el cual se dirige a una pequeña cabaña que se observa al lado derecho y al izquierdo se percibe el ingreso a sanitarios y regaderas, separadas ambos para mujeres y hombres.

Por último, el cuidado de la naturaleza es claramente perceptible, la vegetación es abundante y no se observó destrucción de la misma, por otro lado, la recolección de la basura es realizada por la misma empresa que administra el lugar, de regreso se pudieron observar aves anidando en los árboles y fue posible observar codornices a orilla del camino. 


\section{RESULTADOS}

En la actualidad, el tema de la sustentabilidad ha venido cobrando relevancia, Molina (2006) explica que es en la etapa del turismo industrial donde los recursos existentes son los que determinan el tipo de turismo que se desarrolla. En este sentido, es de reconocer la importancia de una planificación integral, que contemple no sólo los aspectos económicos y sociales, sino que también los ambientales.

Para el caso de la Bahía de Altata la tarea requiere del esfuerzo conjunto entre los actores involucrados en el sistema turístico estatal y municipal, el que pueda ser aplicado en cualquiera de las modalidades o segmentos del turismo, llámese turismo tradicional o de naturaleza como se observa en el esquema, y el cual puede ser adoptado por la localidad.

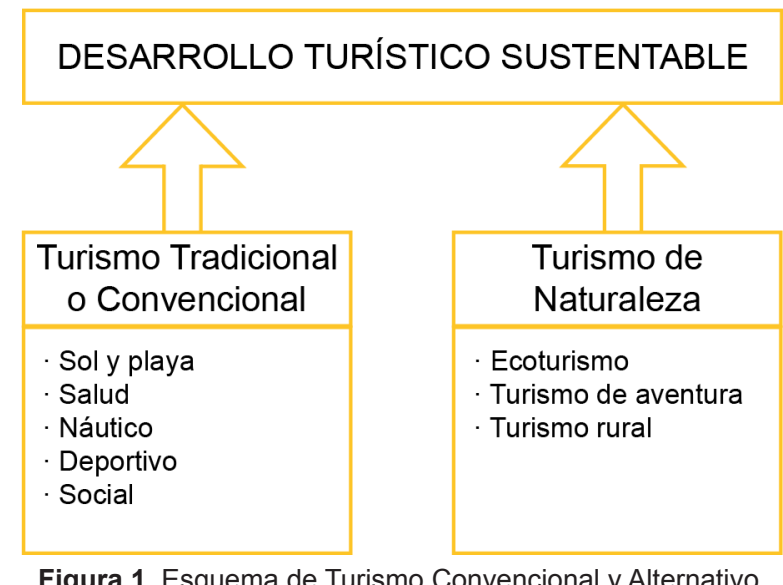

Fuente: Sectur (2004) Turismo Alternativo, Fascículo no. 1

Estas consideraciones permitirán plantear, basados en la definición que tiene la Sectur respecto al turismo alternativo: «Los viajes que tienen como fin realizar actividades recreativas en contacto directo con la naturaleza y las expresiones culturales que le envuelven con una actitud y compromiso de conocer, respetar, disfrutar y participar en la conservación de los recursos naturales y culturales» (Sectur, 2004) y que puedan ser implementadas en la Bahía de Altata, cada uno compuesto por diversas actividades, como las que a continuación se presentan:

- Ecoturismo: este tiene como fin realizar actividades recreativas de apreciación y conocimiento de la naturaleza a través del contacto con la misma (Sectur, 2004). 
- Observación de la naturaleza: En la selva se pueden observar la diversidad de plantas, como el cactus, la biznaga, papaches, choyas, flor de manzanilla y plantas medicinales como la cola de caballo y el ayal.

- Observación de la fauna: La visita a islotes, que sirven de anidamiento de aves marinas, en estos mismos se pueden observar pequeños mamíferos, en la selva existente, la paloma ala blanca, águilas y garzas, y también existen serpientes.

- Senderismo interpretativo: las dunas y grandes extensiones de playa sirven al visitante para transitar a pie o a caballo, equipado con señalamientos del tipo de flora, fauna y características del terreno.

- Talleres de educación ambiental: de las actividades antes mencionadas, se les puede incorporar actividades didácticas, pues en su mayoría involucran contacto directo con la naturaleza e involucrando a su vez a las comunidades locales.

- Turismo de aventura: Los viajes que tienen como fin el realizar actividades recreativas, asociadas a desafios impuestos por la naturaleza (Sectur, 2004).

1. Aire:

- Vuelo en globo: existen extensiones adecuadas para realizar esta actividad.

- Aeromodelismo: vuelo de pequeños aviones de control remoto.

- Vuelo en ultraligero: vuelo controlado en una pequeña aeronave con motor.

2. Tierra

- Caminata: las dunas y extensiones de playa sirven al visitante para transitar a pie, por caminos definidos y guiados por especialistas.

- Ciclismo de Montaña en dunas: las dunas y grandes extensiones de playa sirven al visitante para transitar en bicicleta.

- Cabalgata: las dunas y grandes extensiones de playa sirven al visitante para transitar a caballo, por camino a campo traviesa ya definido. 


\section{Agua}

- Buceo Libre: utilizando equipo básico como visor, aletas y snorkel se pueden observar entre el manglar a peces y cangrejos.

- Kayaquismo: utilización en esteros y bahía de una embarcación de diseño hidrodinámico, de una o dos plazas.

- Pesca recreativa: captura en mar abierto de peces como el dorado, marlín, atún, jureles y pez vela, bajo el concepto de capturar y soltar.

- Turismo rural: son los viajes que tienen como fin el realizar actividades de convivencia e interacción con una comunidad rural (Sectur, 2004).

- Agroturismo: existen terrenos destinados al cultivo y la ganadería rural, ocupado por una sociedad campesina lo que pudiera representar una alternativa económica a través de la combinación y el turismo.

- Talleres Gastronómicos: dar a conocer los platillos típicos de la región como la preparación de mariscos y pescados, barbacoas, tortillas de maíz y harina con grano molido, quesos, asaderas y pan.

En este sentido, el turismo alternativo que se presenta debe ser capaz de «promover un desarrollo integral para las comunidades, mitigando la pobreza (material) a través de la generación de empleo e ingresos económicos complementarios, evitando la migración de su población, fomentando una distribución justa de los ingresos y contribuyendo a la conservación del medio ambiente» (Inostrosa, 2008). 


\section{CONCLUSIONES}

La actividad turística para la Bahía de Altata debe ser entendido como parte del conjunto de actividades productivas que se llevan a cabo en las localidades pesqueras y campesinas, que ayude a ser un factor diversificador de la tradicional y dominante economía turística. Bajo esta lógica, el turismo no se puede convertir en la única fuente de rentas para las familias en la localidad.

La importancia del turismo alternativa radica en los cambios de tendencia donde es el propio turista quien está a la búsqueda de nuevas experiencias y únicas, acorde a sus gustos, necesidades y preferencias.

Aquí el objeto es el de satisfacer las necesidades actuales de las regiones anfitrionas, de los inversionistas turísticos, de los prestadores de servicios turísticos y de los turistas, con el fin de proteger, fortalecer y garantizar las oportunidades de desarrollo en el futuro.

Ante esto, la importancia radica en los cambios de tendencia donde es el propio turista quien está a la búsqueda de nuevas experiencias y únicas, acorde a sus gustos, necesidades y preferencias, como lo es el tener experiencias con las comunidades receptoras, la interrelación con la naturaleza, el de realizar actividades que le impliquen retos físicos, la búsqueda de emociones significativas, el mantenerse en forma, cuidar su salud y, el realizar actividades al aire libre. 


\section{REFERENCIAS BIBLIOGRÁFICAS}

Angrosino, M. (2012). Etnografia y observación participante en Investigación Cualitativa. Editorial Morata. Madrid, España.

Cortés Cortés, M. E. e Iglesias León, M. (2004). Generalidades sobre Metodología de la Investigación». Universidad Autónoma del Carmen, Campeche, México.

Grouch, Geoffrey I. (2007). Modelling destination competitiveness. A Survey and Analysis of the Impact of Competitiveness Attributes. Sustainable Tourism Pty. Queensland. Australia. p. 54.

Diéguez, I., Gueimonde, A., Sinde, A. y Cerradelo, L. (2011). Análisis de los principales modelos explicativos de la competitividad turística en el marco de la sostenibilidad. Cultur. p. 101-124.

Gobierno del Estado de Sinaloa. (1990). Navolato, monografia 1990, Ed. Gobierno del Estado de Sinaloa.

Guimarães, R. P. (2001). La sostenibilidad del desarrollo entre Rio-92 y Johannesburgo 2002: éramos felices y no sabíamos. Ambiente E̊ Sociedade, (9), 1 - 20.

Inostroza, Gabriel V. (2008). Aportes para un modelo de gestión sostenible del turismo comunitario en la región andina. Revista Gestión Turística, 10, Universidad Austral de Chile, 77-90.

IUCN, G., UNEP, U., y WWF, W. (1980). World Conservation Strategy Living Resource Conservation for Sustainable Development. Consultado: 02 de junio de 2016. Disponible en: https://portals.iucn. org/library/efiles/edocs/WCS-004.pdf

Maradiaga C., J. S. (1997). Perfil socioeconómico del Estado de Sinaloa y sus 18 municipios, Ed. UAS, 1a edición.

Medina, X. C. (2008). Caracterización de la industria forestal en España: aspectos económicos y ambientales. España: Fundacion BBVA.

Molina, S. (2006). El posturismo, turismo y posmodernidad. Trillas. México D.F. P. 109. 
Palma, G. (2007). Springbreakers: Turismo salvaje en playas mexicanas/Wild Tourism In Mexican Beaches. Grijalbo. P. 157.

Ritchie, J.R.B. y Grouch, G. I. (2000). The Competitive Destination. Tourism Management, 21, p. $1-7$.

Ritchie, J.R.B. y Grouch, G.I. (2003). The competitive destination: a sustainable tourism perspective. CABI Publishing. Cambridge, Reino Unido.

Secretaria de Turismo (Sectur). (2004). Turismo alternativo, una nueva forma de hacer turismo. Fascículo 1. Serie Turismo Alternativo. México, D.F.

Ventura, V. (2011). El turismo, su cadena productiva, y el desarrollo incluyente en América Latina: los casos de Brasil y México. Serie Comercio y crecimiento inclusivo, 138, 1-81. 


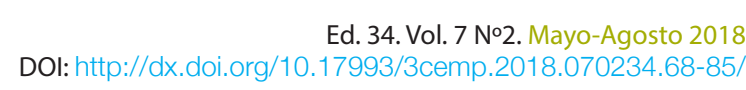


/05/ 


\title{
Plan estratégico para la reactivación económica de San Antonio, municipio de La Paz, Baja California Sur, México
}

Strategic plan for the economic reactivation of San Antonio, La Paz municipality, Baja California Sur, Mexico

\author{
Miguel Ángel Ojeda-Ruiz \\ Profesor-Investigador Tiempo Completo. \\ Universidad Autónoma de Baja California Sur, Campus La Paz. \\ maojeda@uabcs.mx
}

Sergio Antonio Bianchi-Estrada Analista de la Dirección de Vinculación, Innovación y Transferencia de Tecnología, Universidad Autónoma de Baja California Sur, Campus La Paz.

sbianchi@uabcs.mx

José Emer García de la Puente-Orozco Responsable de Vinculación. Universidad Autónoma de Baja California Sur, Campus los Cabos. jegarcia@uabcs.mx

Recepción: 10/06/2017. Aceptación: 22/09/2018. Publicación: 24/05/2018

Citación sugerida:

Ojeda-Ruiz, M.A., Bianchi-Estrada, S.A. y García de la Puente-Orozco, J.E. (2018). Plan estratégico para la reactivación económica de San Antonio, municipio de La Paz, Baja California Sur, México. 3C Empresa: investigación y pensamiento crítico, 7(2), 86-105. DOI: http://dx.doi.org/10.17993/3cemp.2018.070234.86-105/ 


\section{RESUMEN}

El crecimiento acelerado de la industria turística puede ocasionar el subdesarrollo de algunas poblaciones al interior de los polos turísticos generando pobreza y aislamiento, incluso afecta a poblaciones rurales cercanas. Tal es el caso de San Antonio, Baja California Sur (BCS), que se localiza entre los destinos de La Paz y Los Cabos, ambos con una gran afluencia turística y crecimiento poblacional-urbano. A pesar de su cercanía, en un corredor que une ambos destinos, San Antonio no se ha integrado con éxito al desarrollo de la región. Partiendo de un esfuerzo ciudadano, habitantes de la localidad asesorados por la Universidad Autónoma de Baja California Sur, empleando herramientas de planeación estratégica y participativa, elaboraron el Plan Estratégico para la Reactivación Económica de la localidad, que promueve el desarrollo sustentable con base en el patrimonio ambiental y cultural. Este instrumento incorporó conocimiento local, reflexiones de profesores-investigadores, estudiantes, especialistas de instituciones educativas y dependencias de los tres niveles de gobierno. Su estructura comprende cuatro ejes estratégicos congruentes con los Planes de Desarrollo vigentes. Entre sus resultados, destacan la gestión de recursos del Fondo Minero, proyectos arquitectónicos, estructuración de senderos, postular a San Antonio en el programa Pueblos Históricos de BCS y gestiones para la implementación del aviturismo.

\section{ABSTRACT}

The accelerated growth of touristic industry can cause an underdevelopment from some populations in touristic zones creating poorness and isolation; it can even affect other rural dwellers nearby. This is what is happening to San Antonio, Baja California Sur (BCS), it localizes between La Paz and Los Cabos, both cities have large influx of tourists and a big urban population increase. Even though the closeness to both touristic destinations, San Antonio hasn't been successfully integrated to the region development. Starting from a citizen effort, people of this community advised by UABCS and using strategic planning, elaborate the Strategic Plan for the Economic Reactivation of the Locality that promote the sustainable development based on the cultural and environmental heritage. This instrument incorporated local knowledge, reflections of researches professors, specialists and students from educational institutions and different offices from the three government levels. It structure is formed by four strategic stages according to the actual developments plans. Among the results it stand out the management of resources for the "Fondo Minero", architectural projects, trails planning, the postulation of San Antonio to become part of the "Pueblos Historicos" program of SECTUR and incorporate the bird watching touristic activity. 


\section{PALABRAS CLAVE}

Desarrollo regional sustentable, Patrimonio Cultural, Riqueza ambiental, Aviturismo.

\section{KEY WORDS}

Regional sustainable development, Cultural heritage, Environmental wealth, Birdwatching tourism. 


\section{INTRODUCCIÓN}

La falta de integración al desarrollo regional de comunidades rurales es de los principales retos que enfrentan los gobiernos locales, y lo atienden con diversas estrategias que van desde la producción agrícola/ganadera para satisfacer las necesidades regionales hasta la integración a proyectos locales estatales y federales de turismo. Se basan en la riqueza cultural y natural de la zona de interés, articulando planteamientos que surjan del conocimiento local, acorde a las nuevas tendencias de ruralidad, ya sea fomentada por las instituciones de gobierno, o por los propios ciudadanos (PalafoxMuñoz et al., 2016).

Por nueva ruralidad, se entiende al proceso complementario y de opción para el desarrollo rural actual. Esto es, el territorio, sus recursos sociales, culturales y ambientales ahora son considerados todos susceptibles de generar economía local con base en el entramado de diversos productores y empresarios propietarios de la economía de los servicios y la dinámica de las familias del ámbito rural, todo ello en conjunto como sistema generador de bienestar (Hoyos-Castillo y HernándezLara, 2008).

\section{La comunidad de San Antonio ha sufrido deterioro paulatino y una reducción en su población que emigra en busca de oportunidades de desarrollo.}

En años recientes, la noción de sustentabilidad social destaca como factor clave la participación social y el incremento de las capacidades, cualidades y potencialidades humanas, elementos que contribuyen a comprender que la mejora en la calidad de vida debería ser el objetivo principal de los esfuerzos de la sustentabilidad (Foladori, 2007).

La comunidad de San Antonio ha sufrido deterioro paulatino y una reducción en su población que emigra en busca de oportunidades de desarrollo. Esta situación promovió la participación ciudadana en acciones de mejora circunscritas en esquemas de sustentabilidad social, que con la conducción de la Universidad Autónoma de Baja California Sur (UABCS), en un proceso de transferencia de conocimientos dio origen al denominado "Plan Estratégico para la Reactivación Económica de San Antonio Baja California Sur", documento nutrido de aportes de ciudadanos, académicos y estudiantes, fortalecidos con la opinión y experiencia del personal de diversas dependencias de los tres niveles de gobierno. 
El documento tiene el propósito de aportar propuestas, estrategias y alternativas que den certidumbre al desarrollo de la localidad, y que de llevarse a cabo integrarían de manera exitosa a San Antonio en el modelo de desarrollo de la entidad, siendo una experiencia local pertinente y aplicable a muchas localidades rurales del país y del mundo, que viven circunstancias similares. 


\section{CONTEXTOS}

En México, una de las principales actividades económicas es el turismo, industria generalmente ligada a los "Centros Integralmente Planeados" (CIP) desarrollados por el Fondo Nacional de Fomento al Turismo (FONATUR). Desde los años setenta, dos de los principales CIP son Los Cabos y Loreto, sitios que han colocado al estado de BCS como entidad concentrada en el turismo y como principal vector económico generador de divisas y de bienestar. Este hecho ha provocado que el desarrollo se concentre principalmente en estos dos puntos y en la Ciudad de La Paz por ser la capital del Estado, lo que ocasiona "el abandono" de comunidades rurales con poca o nula actividad económica (García de la Puente y Cruz, 2015).

San Antonio es un antiguo pueblo minero que se ubica dentro del Municipio de La Paz a 52 kilómetros de esta ciudad capital por la carretera transpeninsular a San José del Cabo. Debe su origen a los yacimientos de oro y plata que prosperaron con el establecimiento de esta industria, cuyo auge se dio en el siglo XIX y llevó a los poblados sureños de la media península, entre los que se encuentra San Antonio, que en bonanza llego a superar los 10,000 habitantes, algunos de ellos originarios de países como Francia, Italia, China e Inglaterra, quienes llegaron en busca de fortuna (Amado-Manríquez, 1984). Posteriormente, una vez concluidas las actividades mineras en la zona, a principios del siglo XX debido a problemas sociales y económicos, la población fue decreciendo hasta contar actualmente con 463 habitantes (Escandón, 1983).

San Antonio tiene como uno de sus referentes históricos más antiguos la población indígena de los uchitíes, perteneciente a lo que se conocía como la "Nación" de los guaycuras, primer grupo indígena en extinguirse en la península. Al ocurrir esto, el área donde ellos hacían su vida comenzó a ser poblada por colonos españoles y mestizos (Amao, 1997). Esto último ocurrió en el año de 1748, año en que se fundó el Real de Santa Ana, distante de San Antonio apenas unos cuantos kilómetros de tal suerte que la historia de los dos reales quedó ligada a un pasado común (AmaoManríquez, 1984). Destaca, desde sus orígenes, el laborío de las minas que inicialmente fue altamente productivo, pues generó una demanda de insumos para la producción de metales que hizo posible el surgimiento de los primeros ranchos ganaderos de propiedad privada de toda la península (Amao, 1997). Así, el laboreo de las minas y las actividades ganaderas hicieron posible que toda esa área se convirtiera en un detonante del desarrollo regional lo que posibilitó que en el año de 1829 fuera la segunda capital después de Loreto. San Antonio fue durante las primeras décadas del siglo XIX, exportador de metales preciosos y de muchas de las mercaderías mencionadas. Las actividades mineras y ganaderas que surgieron en los reales de minas hicieron posible no solamente 
el poblamiento de esa parte de la península sino también el de La Paz, puerto por donde entraban los insumos para la producción de metales (Altamirano, 1971).

Cuando se hace referencia al medio ambiente de BCS es común el visualizar extensas zonas áridas compuestas en su mayoría por cactáceas y matorrales micrófilos y espinosos característicos de zona áridas y semiáridas. Sin embargo, cerca de la localidad se encuentra emplazada la Reserva de la Biosfera de la Sierra de la Laguna, que debido a sus características físicas cuenta con la presencia de dos ambientes únicos en el estado: la selva baja caducifolia y el bosque de pino encino, estos se encuentran presente debido a su altitud de $1300 \mathrm{mt} / \mathrm{snm}$ y su latitud dentro de los trópicos (Rzedowsky, 1978). Dichos ambientes le brindan unicidad de especies que aunado a las barreras físicas geográficas y geológicas permiten que se genere el fenómeno del endemismo siendo sobresaliente en el grupo de las aves (García de la Puente, 2011). Cabe señalar que dicha reserva colinda con San Antonio, que acumula los promedios anuales de lluvia más altos de la entidad.

\section{A pesar de la riqueza cultural, natural y sus características geográfico- ambientales, el pueblo de San Antonio no ha logrado desarrollar en tiempo reciente ninguno de sus potenciales.}

El aviturismo es hoy la actividad con mayor crecimiento a nivel mundial del turismo alternativo. Este se define como la observación y correcta identificación de aves en su medio natural. Se destaca en Estados Unidos Canadá e Inglaterra con mayor número de practicantes (Cantú et al., 2011). En general, el estado posee un gran potencial para la implementación de esta actividad por su cercanía con Estados Unidos y su gran diversidad de ambientes, dicha actividad es practicada de manera independiente por turistas aislados que visitan la región de San Antonio y el estado en general, debido a su riqueza de especies, a pesar de no contar con un aprovechamiento organizado de la actividad principalmente por desconocimiento (García de la Puente, 2015).

A pesar de la riqueza cultural, natural y sus características geográfico-ambientales, el pueblo de San Antonio no ha logrado desarrollar en tiempo reciente ninguno de sus potenciales. Por lo cual, desde hace algunos años, las tendencias muestran un decrecimiento en la población de esta comunidad, y en apariencia que no se cuenta con una visión clara y compartida del futuro que se pudiera lograr. Incluso algunos miembros de la comunidad perciben un "abandono" por parte de los gobiernos debido a la falta de una propuesta integral de desarrollo, que ante todo, pretenda mejorar las condiciones de bienestar de sus habitantes. 


\section{OBJETIVO DEL PLAN}

El proceso de planificación definió los siguientes objetivos para el instrumento:

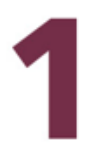

Mejorar la capacidad productiva mediante obras de infraestructura que optimicen, aprovechen y den paso a esta nueva industria, aprovechando el potencial Natural e Histórico de productos turísticos con que cuenta la región e integrar a los actores que conformarán el sector; para permitir hacer del Real un lugar atractivo y por consiguiente el ingreso a este nuevo mercado.

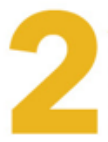

Asegurar una actividad ag. ropecuaria dinámica y com. petitiva a largo plazo, a fin de aprovechar la estratégica posición geográfica del Real, su clima y sus biodiversidades tanto endémica como especies introducidas en sus tierras cultivables y con capacidad de explotación agrícola, permitiendo aprovechar sus vías de comunicación terrestre en los dos mercados locales importantes.

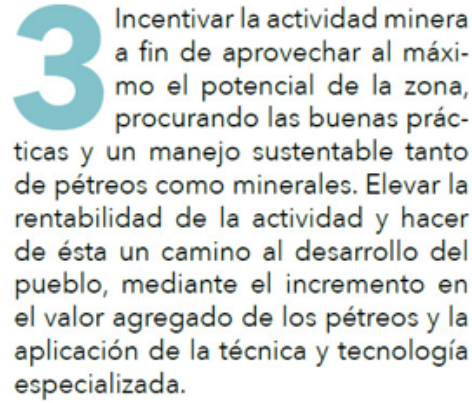

Incentivar la actividad minera a fin de aprovechar al máximo el potencial de la zona procurando las buenas prácticas y un manejo sustentable tanto de pétreos como minerales. Elevar la rentabilidad de la actividad y hacer de ésta un camino al desarrollo de pueblo, mediante el incremento en especializada.

\section{METODOLOGÍA}

El trabajo se desarrolló utilizando la metodología de planeación estratégica (Toselli, 2015) y planeación participativa (Gorenstein, 2015) considerando las experiencias de Popovich y Toselli (2006) en la integración de un programa de seminario-taller en el que participaron: habitantes de la comunidad, UABCS, Instituto Tecnológico de La Paz, Secretaria de Desarrollo Económico, Medio Ambiente y Recursos Naturales del Gobierno del Estado de B.C.S., Secretaría de Turismo de Baja California Sur, H. XV Ayuntamiento de La Paz, Dirección de Turismo Municipal del H. XV Ayuntamiento de La Paz, Dirección General de Obras Públicas y Asentamientos Humanos del H. XV Ayuntamiento de La Paz y el Instituto Municipal de Planeación de La Paz.

El programa consideró como prioritarias las siguientes etapas:

1. Identificación de los actores comunitarios. Se llevó a cabo un análisis con la participación de habitantes de la localidad con la finalidad de lograr una sinergia de trabajo exitosa, además, con la asesoría institucional se formalizó la constitución de una asociación civil, en pro del desarrollo de la localidad.

2. Caracterización de las actividades económicas de la región y su potencial. Ésta caracterización se elaboró en 3 vertientes: 
- Histórico-cultural

Consiste en un recuento de los acontecimientos relevantes desde la fundación del Real de Santa Ana resaltando el patrimonio histórico del poblado de San Antonio.

- Ambiental

A través de un análisis de las condiciones del entorno, se determinaron actividades acordes a la conservación ambiental de la localidad.

- Socioeconómica

Se compone de estadísticas de las actividades económicas preponderantes de la región y demografía.

3. Desarrollo de elementos estratégicos del Plan: Misión, Visión, Valores y Principios

4. Problematización y priorización de las necesidades para el desarrollo regional

Identificación y orientación de necesidades a través de un análisis de consistencia con los planes de desarrollo estatal y municipal, con la intención establecer programas acordes a las iniciativas de los 3 niveles de gobierno, asegurar la obtención de recursos y la búsqueda de fondos.

5. Estructura del plan por ejes estratégicos

Se elaboró un plan conformado por cuatro ejes estratégicos con objetivos, metas, programas, actividades y un sistema de evaluación con la finalidad de que estos elementos en conjunto permitan a través de la planeación estratégica y participativa establecer un ciclo flexible a los cambios de administración gubernamental. 


\section{RESULTADOS}

1. Se constituyó Real de Minas de San Antonio Asociación Givil (A.G.) como actor clave dentro de la comunidad con la función de promover y gestionar recursos para la implementación del plan. La A.C. Está conformada por habitantes de la localidad, con liderazgo reconocido entre la población, y tiene el propósito de contribuir a la mejora de los niveles de bienestar de los habitantes del poblado.

2. Caracterización Histórico-Cultura, Ambiental y socioeconómica. En San Antonio se aprecia un paisaje cultural expresado en un patrimonio histórico de primer orden con antiguos senderos y caminos, viejas casonas catalogadas como monumentos históricos nacionales que constituyen evidencias de modos de vida ya desaparecidos. La zona geográfica se localiza entre la selva baja caducifolia y los primeros bosques de encinos. El bioma formado destaca como uno de los sitios con el mayor potencial para el avistamiento de aves por su particular composición ambiental, y se localiza en una zona de transición hacia el área de bosque de pino encino e integración dentro del complejo de la reserva de la biósfera de la Sierra de la Laguna. A pesar de haberse caracterizado por su legado histórico soportado por la actividad minera, actualmente la principal actividad económica preponderante es el sector pecuario de acuerdo a la Secretaria de Agricultura, Ganadería, Desarrollo Rural, Pesca y Alimentación. El tipo de ganado de mayor preponderancia es el bovino con $87 \%$ de participación seguido del caprino con $11 \%$ y ovino con $2 \%$.

La dinámica poblacional de San Antonio muestra una caída desde el Censo de 1990 hasta el Censo del año 2010, pasando de 962 habitantes a 463 respectivamente. Es importante destacar que para 2010 la proporción de ciudadanos con 18 años o más, fue del $70 \%$.

La mayor parte del poblado cuenta con servicios públicos de electricidad y, aunque se carece de una red de drenaje y alcantarillado, las viviendas cuentan con equipamiento de sistema drenaje de tipo fosa séptica.

3. Misión, Visión, Valores y Principios. Derivado de un ejercicio participativo, los integrantes de Real de San Antonio A.C. tenemos una clara imagen objetivo de lo que aspiramos para nuestra tierra, y sobre todo para todos sus habitantes, ideal que simpatiza con las aspiraciones de su población. 


\section{MISIÓN}

Somos un grupo ciudadano proactivo e incluyente, que trabaja para contribuir en la mejora de los niveles de bienestar de los habitantes de San Antonio, a través del uso de las vocaciones territoriales y capacidades productivas de la región de acuerdo al tejido social, utilizando como ejes principales el rescate histórico del patrimonio cultural y el uso responsable y productivo de su entorno ambiental.

\section{VISIÓN AL 2020}

San Antonio y sus habitantes tendrán mejores indicadores de bienestar y calidad de vida a través de un modelo de desarrollo local integrado con éxito en lo global, que ha permitido revalorar su patrimonio histórico, cultural, natural y lograr una economía diversificada nutrida de actividades culturales, turísticas, agropecuarias, mineras y de servicios, siendo una comunidad reconocida por sus prácticas de sustentabilidad.

\section{VALORES Y PRINCIPIOS}

Entre los principales se definieron los siguientes: Sentido de pertenencia, Pro-actividad, Compromiso social, Participación ciudadana, Riqueza histórica-cultural, Tolerancia, Uso de las vocaciones naturales con enfoque sostenible, Desarrollo local y natural.

\section{Programa de acción y aplicación para la integración del turismo a la comunidad.}

A continuación se enuncian los ejes estratégicos propuestos, así como un análisis de consistencia con los planes de desarrollo estatal y municipal:

1. Infraestructura y servicios básicos de la comunidad

2. Reactivación de vocaciones económicas

3. Turismo cultural y de naturaleza.

4. Desarrollo humano social e incluyente. 


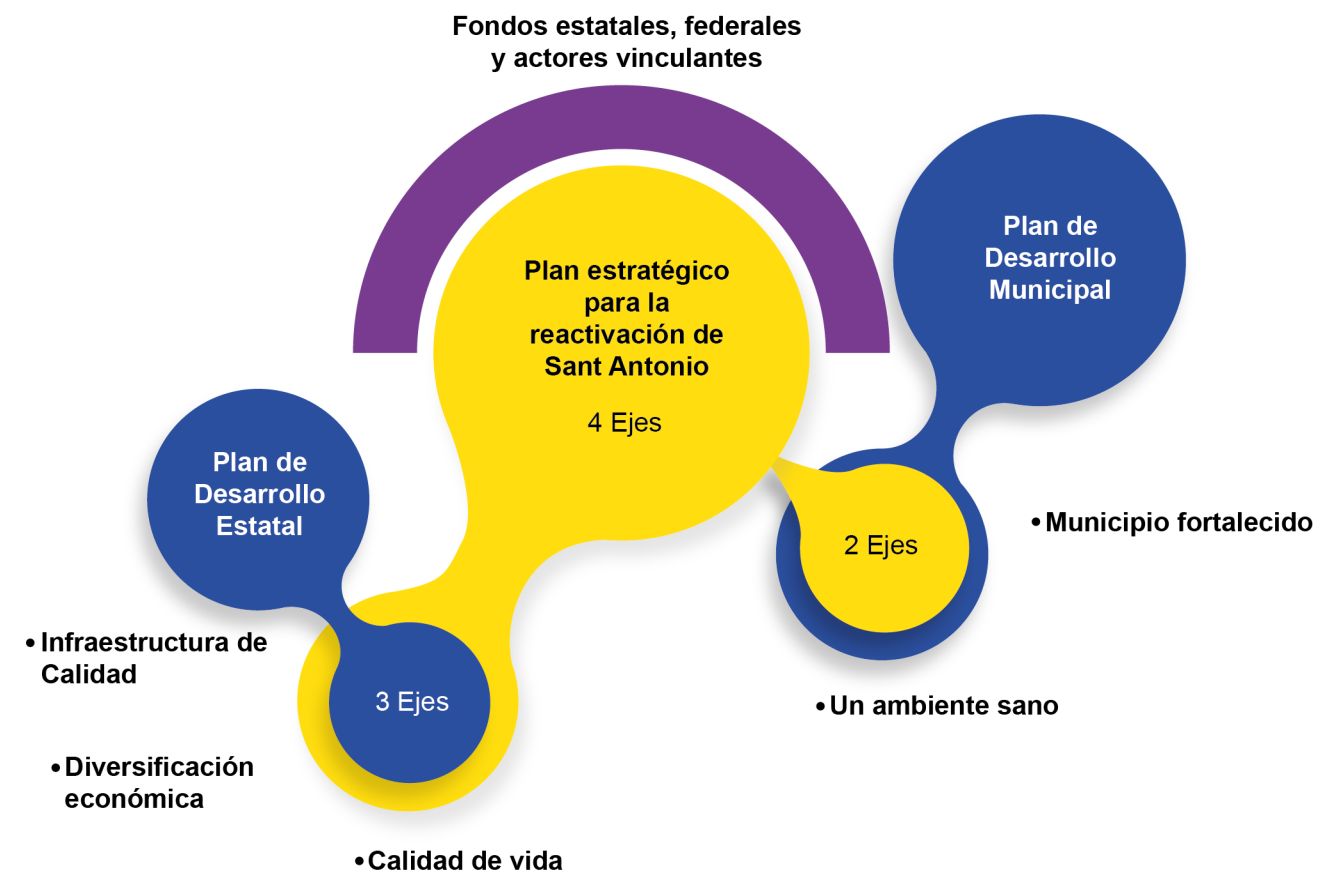

Figura 1. Análisis de consistencia con los Programas de Desarrollo Estatal y Municipal. 


\section{Estructura del plan estratégico por ejes.}

\begin{tabular}{|c|c|c|}
\hline & EJE & EJE \\
\hline & $\begin{array}{l}\text { E1. Infraestructura y servicios básicos de } \\
\text { calidad } \\
\text { Desarrollar la infraestructura adecuada que } \\
\text { fomente la capacidad productiva y ofrezca } \\
\text { calidad de vida a la población, sostenibilidad } \\
\text { ambiental y desarrollo económico. }\end{array}$ & $\begin{array}{l}\text { E2. Reactivación de vocaciones económicas } \\
\text { Propósito: Implementar estrategias que } \\
\text { permitan la inclusión de productores locales e } \\
\text { inversionistas en la diversificación y desarrollo } \\
\text { de actividades económicas del Real de San } \\
\text { Antonio de acuerdo con la riqueza natural y el } \\
\text { patrimonio histórico de la región. }\end{array}$ \\
\hline & METAS & METAS \\
\hline \multirow[t]{3}{*}{$\begin{array}{l}\text { ESTRUCTURA } \\
\text { DEL PLAN } \\
\text { ESTRATÉGICO } \\
\text { POR EJES }\end{array}$} & $\begin{array}{l}\text { M1. El poblado de San Antonio cuenta con los } \\
\text { documentos legales y normativos necesarios } \\
\text { que orienten el crecimiento ordenado y } \\
\text { sustentable de la localidad }\end{array}$ & $\begin{array}{l}\text { M2. Los productores agrícolas y ganaderos } \\
\text { de la localidad participan en cadenas de valor } \\
\text { que favorecen la inclusión y su desarrollo } \\
\text { en atención a las necesidades alimentarias } \\
\text { regionales y estatales. } \\
\text { M3. Los habitantes de San Antonio cuentan } \\
\text { con alternativas de impacto social y desarrollo } \\
\text { urbano positivo para aprovechar el potencial } \\
\text { y la vocación de actividades relacionas a la } \\
\text { minería. } \\
\text { M4. Los recursos y actividades primarias } \\
\text { desarrolladas en el poblado de San Antonio } \\
\text { tienen valor agregado para el desarrollo } \\
\text { industrial de la región. }\end{array}$ \\
\hline & OBJETIVOS & OBJETIVOS \\
\hline & $\begin{array}{l}\text { OE1. Promover el desarrollo urbano ordenado } \\
\text { y mecanismos de gestión comunitaria. } \\
\text { OE2. Asegurar la disponibilidad y calidad de } \\
\text { los servicios públicos. } \\
\text { OE3. Detonar la infraestructura básica de } \\
\text { soporte al plan de reactivación económica. }\end{array}$ & $\begin{array}{l}\text { OE4. Promover la inclusión y desarrollo de } \\
\text { productores agrícolas y ganaderos locales en } \\
\text { cadenas alimentarias de valor que atiendan } \\
\text { las demandas del estado, particularmente de } \\
\text { los municipios de La Paz y Los Cabos. } \\
\text { OE5. Promover el uso de los recursos } \\
\text { geológicos mediante aprovechamiento de los } \\
\text { recursos mineros metálicos y no metálicos } \\
\text { de la región para la minería, incluso con } \\
\text { propósitos culturales y turísticos. } \\
\text { OE6. Vincular a los productores de la región } \\
\text { con organizaciones de educación y de la } \\
\text { sociedad civil para elaborar proyectos de } \\
\text { inversión que logren la industrialización de } \\
\text { productores obtenidos en la zona en atención } \\
\text { a las capacidades productivas locales. }\end{array}$ \\
\hline
\end{tabular}




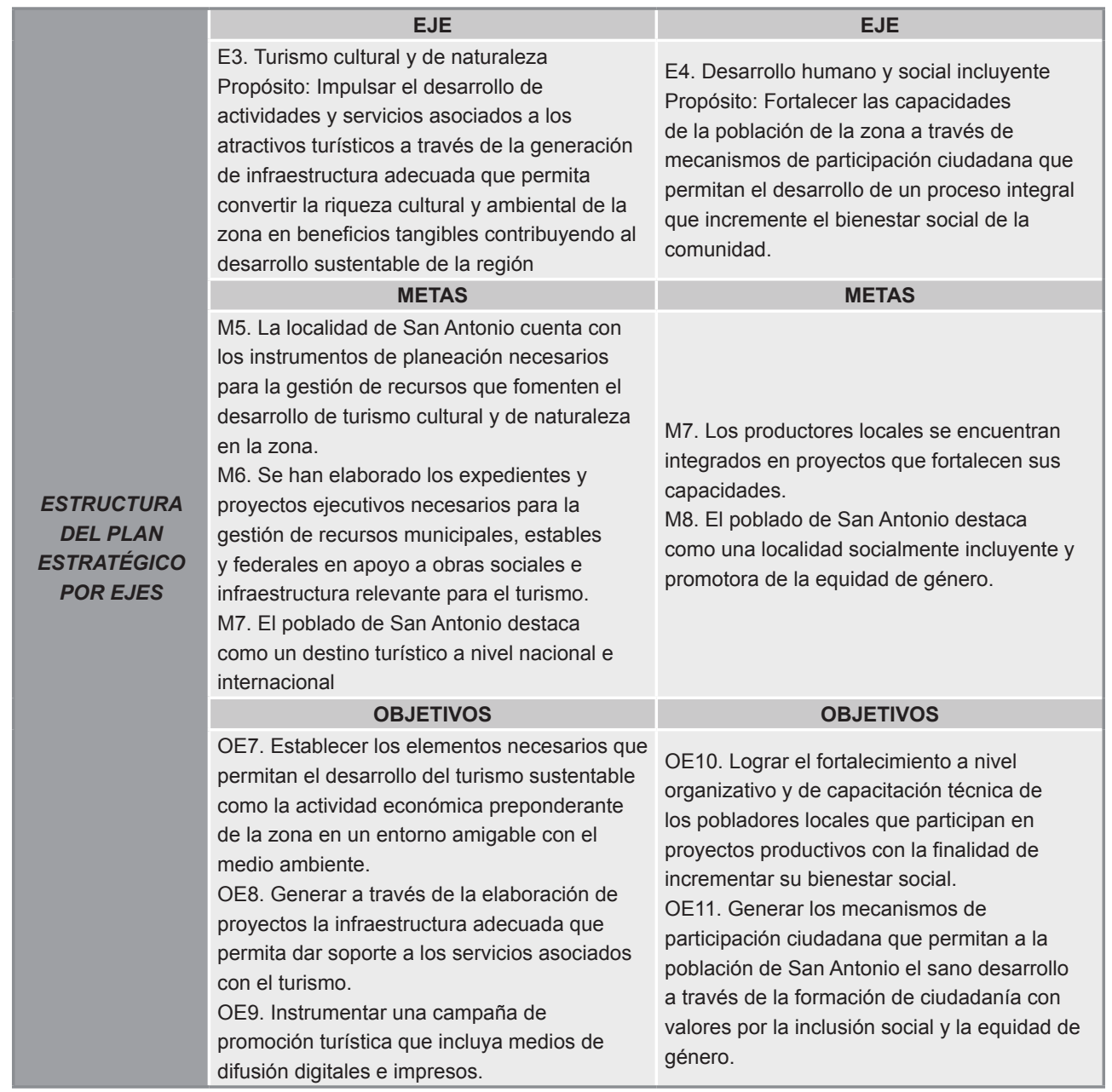

\section{Primeros resultados de la implementación del Plan.}

Además de las sinergias que se lograron con el proceso, hay resultados tangibles de su implementación, entre los que destacan:

- A través de la Secretaría de Desarrollo Agrario, Territorial y urbano se participó en el programa Fondo para el Desarrollo Regional Sustentable de Estado y Municipios Mineros y 
actualmente se gestionan $\$ 6,000,000.00 \mathrm{MXN}$ en diversas obras para beneficio del poblado.

- Con la participación de la Secretaría de Turismo del Estado de BCS se sometió un proyecto para la Integración e Implementación de un Modelo Estatal de Desarrollo del Aviturismo, el proyecto plantea la inclusión de los lugares con potencial aviturístico a la diversificación económica e integración al sistema de proveeduría interna Estatal. Se espera gestionar un presupuesto de $\$ 5,000,000.00 \mathrm{MN}$ para formación de capital humano, generación de infraestructura y servicios necesarios para el aviturismo contemplando a San Antonio dentro de la primer etapa del proyecto.

- Como parte de la articulación con actividades y programas de los distintos niveles de gobierno, se sometió a la Secretaría de Turismo del Estado una propuesta para integrar al poblado de San Antonio en el Programa de Pueblos Históricos para el Ejercicio Fiscal 2017, se llevó a cabo una evaluación de los activos turísticos e históricos de la localidad incluyendo casas y senderos entre otros y actualmente se espera el dictamen de la Secretaría para la inclusión al programa. 


\section{CONCLUSIONES}

El objetivo del presente proyecto fue elaborar una herramienta de articulación y gestión que facilite la reactivación económica de una comunidad rural, como muchas en México, que por diversos factores ha quedado excluida o rezagada en el desarrollo. La metodología aplicada, ampliamente conocida, fue adaptada de acuerdo a experiencias anteriores demostrando ser útil y exitosa sobre todo si se enfoca como un programa de seminarios con actores principales y representantes de organismos relevantes en el desarrollo local.

El proceso de transformación de San Antonio cuenta ya con el apoyo de la comunidad local y académica, así como respaldo de un importante número de oficinas y funcionarios clave.

La experiencia expuesta muestra que el esquema de participación comunitaria es esencial, apoya la descentralización y opera en favor de los ciudadanos cuando pierden eficacia los mecanismos tradicionales impulsados desde el gobierno. Éste caso de estudio muestra que es posible lograr cohesión para autogestionar recursos propios y decidir sobre su uso en forma autónoma y dirigida a la integración productiva, a la inclusión a partir del trabajo y al desarrollo económico sustentable.

El proceso de transformación de San Antonio cuenta ya con el apoyo de la comunidad local y académica, así como respaldo de un importante número de oficinas y funcionarios clave que tuvieron la posibilidad de interactuar en la construcción del documento, lo que seguramente ayudará en la gestión de programas y proyectos específicos. A pesar de ello, su estructura final con enfoque de mercado para facilitar su comprensión, requerirá en el corto plazo consolidar el respaldo del gobierno municipal y de las delegaciones federales que son ventanillas de diversos programas para el desarrollo local. Otro uso del documento es la gestión de organizaciones sin fines de lucro o por donaciones de empresas, para ello fue clave impulsar desde etapas tempranas la integración de una Asociación Civil.

El sustento del documento sobre el patrimonio ambiental y cultural de la localidad encierra un importante trasfondo en la concepción del bien sustentable y cultural. A este campo, supone la inclusión de tres variables, que antes solían obviarse, y que resultan fundamentales para comprender en sentido amplio el concepto de patrimonio cultural en detrimento del patrimonio histórico. Se trata del carácter inmaterial e intangible presente en este tipo de bienes, su carácter de representación cultural y la intrínseca relación entre la vertiente cultural y natural que simultáneamente se da en muchos de ellos. 


\section{REFERENCIAS BIBLIOGRÁFICAS}

Altamirano, F. (1971). Exploración por oro y plata en Baja California Sur: 4 Seminario Interno Anual sobre exploración Geológico Minera. Consejo de Recursos Naturales no Renovables, México D.F. : 3-28.

Amao-Manríquez, J.L. (1984). Origen y desarrollo de la minería en Baja California Sur: Simposio sobre la historia de Baja California, La Paz, BCS : 17-27.

Amao-Manríquez, J.L. (1997). Mineros misioneros y rancheros de la antigua California. Instituto Nacional de Antropología e Historia, México, DF. 168 p.

Cantú, J.C., Gómez de Silva, H. y Sánchez, M.E. (2011). El dinero vuela: El valor económico del ecoturismo de observación de aves. Defenders of Wildlife, Washington, EEUU.

Escandón, F. (1983) Análisis de los trabajos geológico-mineros efectuados en el distrito de San Antonio, El Triunfo, BCS, y evaluación económica preliminar. Consejo de Recursos Minerales.

García de la Puente O., J.E. y Gruz Ghávez, P.R. (2015). Potencial Económico del aviturismo en Los Cabos. Revista Global de Negocios, (3) 29-43.

García de la puente Orozco, J.E. (s.d). Fichas técnicas de la identificación para el proyecto: acervo fotográfico de aves rapaces, B.C.S., México. Universidad Autónoma de Baja California Sur. La Paz, B.C.S., México. 53 p.

García de la Puente, J.E. (2015). Viabilidad y compatibilidad del aviturismo con la observación de ballenas en la Laguna Ojo de Liebre, B.C.S., México. Tesis de Maestría, Universidad Autónoma de Baja California Sur, La Paz, México.

Gesto. Gestión y Valorización Del Patrimonio Gultural. S.L. La protección del patrimonio cultural: ordenación del territorio y gestión del patrimonio en la Alpujarra media granadina (*). Disponible en: http://revistaseug.ugr.es/index.php/erph/article/viewFile/3314/3327

Gorenstein, S. (2015). Transformaciones territoriales contemporáneas: Desafíos del pensamiento latinoamericano. EURE (Santiago), 41(122), 5-26. 
Hoyos Castillo, G., y Hernández Lara, O. (2008). Localidades con recursos turísticos y el Programa Pueblos Mágicos en medio del proceso de la nueva ruralidad. Los casos de Tepotzotlán y Valle de Bravo en el Estado de México. Quivera, 10(2).

Manzanal, M. (2004). Instituciones y gestión del desarrollo rural en la Argentina degradada: hacia la reconstrucción de la nación. Economía, Sociedady Territorio, (4)15. Disponible en: http:/ / est. cmq.edu.mx/index.php/est/article/view/416/817

Palafox-Muñoz, A., Martínez-Perezchica, M. G., y Anaya-Ortiz, J. S. (2016). Nueva ruralidad y sustentabilidad social en el pueblo mágico de Calvillo, Aguascalientes. RITURRevista Iberoamericana de Turismo, 6(1), 64-81.

Popovich, M. R., y Toselli, G. (2006). Planificación estratégica participativa y comunidad local. Desarrollo de un destino turístico en Argentina. Cuadernos de turismo, (17), 167-188.

Rzedowsky, J. (1978)Vegetación de México. Ed. Limusa, México, DF. 432pp.

Toselli, C. (2015). Turismo, Planificación Estratégica Y Desarrollo Local. TURyDES, 8(18). 


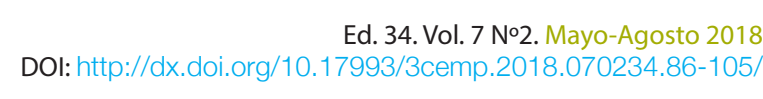




\section{Consejo Editorial}

Director

Editores adjuntos

Editores asociados
Víctor Gisbert Soler

María J. Vilaplana Aparicio

Inés Poveda Pastor

Vicente Sánchis Rico

David Juárez Varón

F. Javier Cárcel Carrasco 


\section{Comité Científico Técnico}

Área textil

Área financiera

Organización de empresas y RRHH

Estadística; investigación operativa

Derecho

Ingeniería y tecnología

Tec. de la información y la comunicación

Medicina y salud
Prof. Dr. Josep Valldeperas Morell

Universidad Politécnica de Cataluña, España

Prof. Dr. Juan Ángel Lafuente Luengo

Universidad Jaume I; Castellón de la Plana, España

Prof. Dr. Francisco Llopis Vañó

Universidad de Alicante, España

Prof. Dra. Elena Pérez Bernabéu

Universidad Politécnica de Valencia, España

Prof. Dra. María del Carmen Pastor Sempere

Universidad de Alicante, España

Prof. Dr. David Juárez Varón

Universidad Politécnica de Valencia, España

Prof. Dr. Manuel Llorca Alcón

Universidad Politécnica de Valencia, España

Dra. Mar Arlandis Domingo

Hospital de San Fuan de Alicante, España 